\title{
Spatiotemporal indicators of solar energy potential in the Guiana Shield using GOES images
}

\section{Erwann Fillol ${ }^{\mathrm{a}}$, Tommy Albarelo ${ }^{\mathrm{a}}$, Antoine Primerose ${ }^{\mathrm{a}}$, Lucien Wald ${ }^{\mathrm{b}}$ and Laurent Linguet $^{\mathrm{a}^{*}}$}

${ }^{a}$ Université de Guyane, UMR 228 Espace-DEV, IRD, Université de Montpellier, Université de la Réunion, 275 Route de Montabo, BP 165, 97323 Cayenne Cedex, Guyane Française tommy.albarelo@ird.fr, erwann.fillol@gmail.com, antoine.primerose@univ-guyane.fr. laurent.linguet@univ-guyane.fr

${ }^{b}$ MINES Paris Tech, PSL Research University, Centre Observation, Impacts, Energy, BP 204, 06905, Sophia Antipolis Cedex, France lucien.wald@mines-paristech.fr

* Corresponding author

Abstract: The purpose of this article is to evaluate the potential for solar energy in the Guiana Shield and propose indicators to encourage the exploitation of solar energy systems in this area. For this, we use the Heliosat-2 optimized method to process images from the geostationary meteorological satellite GOES acquired in the period from April 2010 to July 2015. We calculated the average daily global horizontal irradiation (GHI) and direct normal irradiation (DNI) throughout the study period. The results obtained allowed us to establish four indicators: maps of production potential, the inter-day variability of DNI and GHI, maps of solar panel orientation related to maximum solar potential, and maps of areas where the solar resource is under the exploitable potential threshold. We also added an additional indicator, the suitability of areas for solar system installation depending on the ground slope. Our study shows that the average value of production potential for the entire Guiana Shield is approximately $1780 \mathrm{kWh} \cdot \mathrm{kWc}^{-1}$.year ${ }^{-1}$ for GHI and $2040 \mathrm{kWh} \cdot \mathrm{kWc}^{-1}$.year ${ }^{-1}$ for DNI. Comparisons with pyranometer measurements indicate an error relative bias of less than $2 \%$ and a relative RMSE of less than $21 \%$ for hourly estimates of GHI. Although the Guiana Shield region is covered by many clouds, few areas show insufficient solar potential for the exploitation of GHI and DNI, but the hilly nature of the area limits possible locations of very large power plants and instead favors more medium-sized plants. This is the first study that offers exploitability indicators for solar resources in the Guiana Shield. In conclusion, the established indicators provide a new perspective on the solar potential in the Guiana Shield and are expected to promote the development of new solar energy operating systems.

Keywords: renewable energy, solar irradiation, indicators, suitability areas, Guiana Shield, Heliosat-2. 


\section{Introduction}

Climate change is largely due to emissions of greenhouse gases created by human activity. Without a mitigation strategy, the average temperature on the Earth's surface could increase by between $3.7^{\circ} \mathrm{C}$ and $4.8^{\circ} \mathrm{C}$ before 2100 (IPCC, 2014). The electricity generation sector is the primary sector in which carbon emissions can be quickly reduced. In particular, the renewable energy sector is promising because of its low environmental impact. Among the available forms of renewable energy, photovoltaics has the most global future potential. According to the International Energy Agency (IEA) [1], the worldwide installed capacity of photovoltaic power has been experiencing significant growth for several years and shows growth prospects of about $40 \mathrm{GW} /$ year from 2015 to 2020 . At the end of 2014, the worldwide installed capacity was approximately $177 \mathrm{GW}$, divided in the following manner: $51 \%$ in Europe, $36 \%$ in Asia, $12 \%$ on the American continent (21 GW mainly installed in North America), and $1 \%$ in Africa. One reason for the growth of photovoltaics is related to the falling cost of photovoltaic systems by $50 \%$ between 2010 and 2014. This cost reduction offers new opportunities to provide electricity to millions more people around the world.

Indeed, photovoltaics is increasingly seen as an effective and economical way to supply electricity to isolated areas rather than extending electricity networks. Another advantage that may encourage the use of solar energy in developing countries is that it is relatively well distributed over a large part of the planet, and much more abundant near the equator. However, several regions in the world located near the equator have a poorly developed capacity for energy production based on solar power. This is the case in the Guiana Shield area in the north of South America. In 2015, according to IEA, the maximum net capacity of installed photovoltaic (PV) capacity in the countries of the Guiana Shield was 0 MW in Suriname, 2 MW in Guyana, and 3 MW in Venezuela. There are few or virtually no solar power plants in Amapá, North Brazil, while French Guiana has installed 39 MW [2-5]. Electrical networks are underdeveloped and electricity production of the Guiana Shield countries is mostly fossil dependant (diesel generators) or hydroelectric. The poor development of solar power generation projects is almost certainly related to a lack of knowledge regarding the solar energy potential in this region.

Development of solar power generation projects in the Guiana Shield can only be accomplished with increased knowledge of the solar radiation potential and its variability in this region. This knowledge can be achieved through a network of terrestrial solar radiation measuring stations. Although in-situ data interpolation allows acquisition of solar radiation maps, the data interpolation is valid only up to an average distance of $50 \mathrm{~km}$ between stations for daily radiation totals and up to $34 \mathrm{~km}$ between stations for hourly radiation measurements [6]. Beyond this distance, it is recommended that satellite imagery is used to obtain significant results.

Solar radiation potential is generally derived from satellite imagery by using models that can be categorized as physical, statistical and semi-empirical. The physical models offer 
more generality, however, they are complex and require atmospheric data (aerosol properties, precipitable water, ozone, cloud fraction, optical depth, effective radius, height, phase, aerosol optical depth, etc.) as input to a Radiative Transfer Model (RTM). The RTM models the effects of the atmosphere on the incoming solar radiation to generate estimates of surface solar radiation [7, 8]. Statistical models have an advantage of simplicity, they usually use a parameter called "cloud index" defined as a function of the reflectance of the ground (i.e., without clouds or minimal albedo) and the reflectance of very bright clouds [9]. Solar radiation at the Earth surface is obtained by linking the cloud index to the irradiance obtained under clear skies [10, 11]. Moreover, semi-empirical model combine the use of a RTM and the calculation of a cloud index [12, 13]

Among the existing methods for estimating solar potential from satellite images, one is widely exploited by the scientific community: the Heliosat-2 method [9-10]. The Heliosat-2 method uses input data from the visible channel of the Meteosat satellite and a cloud index coupled with a clear sky model to estimate solar radiation on the ground. The spatial coverage of data is identical to the spatial extent of the images of the Meteosat geostationary meteorological satellite (Europe, Africa, Middle East and western part of the South America continent). The solar radiation data is provided every 15 minutes with a spatial resolution of $0.03^{\circ} \times 0.03^{\circ}$ (about $3 \mathrm{~km} \times 3 \mathrm{~km}$ ). This method was optimized by Albarelo et al. in 2015 [14] to produce estimates of solar radiation in western South America using images from the visible channel of the GOES-E satellite. To address the lack of mapping of solar potential and its features in the Guyana Shield area, we use the Heliosat- 2 method optimized by Albarelo et al. The effectiveness of this Heliosat- 2 optimized method has been evaluated in one of the countries of the Guyana Shield (French Guyana) with conclusive results that allow its use on a larger scale.

This study aims to produce information currently lacking on the usability of solar radiation. There are several studies in the tropics on solar potential, predominantly regarding global radiation in the horizontal plane (global horizontal irradiation - GHI) and occasionally regarding direct radiation normal to the incident surface (direct normal irradiance - DNI). These include the work of Janjai et al. [15-16] on mapping of the solar potential in Southeast Asia, that of Gastli \& Charabi [17] on the Middle East, and of Pillot et al. [18] in Djibouti. The solar potential of Brazil was also evaluated in the SWERA (Solar and Wind Energy Resources Assessment), which resulted in the design of the Brazilian Atlas of Solar Energy [19]. Estimates of GHI and DNI from this atlas were obtained using the Brasil-SR estimation method [20-22]. This is a physical model that combines weather and climate data with GOES satellite images in the visible and infrared channel.

Other solar potential studies have done more than simply map the solar potential. Some studies have integrated the analysis of constraints operability including Polo et al. [23], who conducted a study of solar potential in Vietnam by analyzing the constraints related to a minimum level of potential in terms of GHI as DNI, in order to optimize the operation and productivity of PV plants (to exploit the GHI) and concentrator solar power, or CSP (to 
exploit the DNI). Another example is Mahtta et al. [24], who also conducted a study of solar potential through DNI and GHI in India. They analyzed the constraints related to the minimum irradiation threshold $\left(4 \mathrm{kWh} \cdot \mathrm{m}^{-2}\right.$.day ${ }^{-1}$ for GHI-1, $5.47 \mathrm{kWh} \cdot \mathrm{m}^{-2}$.day ${ }^{-1}$ for DNI), but also the constraints related to the type of land (only land classified as "wasteland" was used) and the slope (less than $2.1 \%$ ). Gherboudj \& Ghedira [25] carried out even more research on this issue. They estimated the potential of GHI and DNI in the United Arab Emirates, and they studied the constraints on the production capacity of solar systems, such as climatic factors that may impact system productivity (humidity, wind, aerosol particle size, temperature). Others constraints were also analyzed, such as topography, vegetation, and the presence of roads, which limit availability of production areas.

However, to our knowledge no study exists that deals with solar potential and constraints related to the use of solar energy in the Guiana Shield. This study seeks to fill this gap and aims to map the solar potential of the area and identify the most suitable areas for the operation of solar power systems. This knowledge is vital for overcoming the barrier to developing production projects based on solar energy. To carry out this study, we build indicator maps relating to the usability of solar energy production systems. Following this work, we identify the most suitable areas for the deployment of solar energy production systems. This study is part of a genuine effort to promote the development of solar energy exploitation in the Guiana Shield. The article is structured as follows: the study area and data is presented in Section 2. Section 3 describes the methodology used to convert a satellite image map of solar radiation. In Section 4, the results are presented and discussed. Finally, we present conclusions and our future research prospects.

\section{Data}

The Guiana Shield is a region of South America composed of Venezuela, Guyana, Suriname, French Guiana, and northern Brazil (states of Pará, Amapá, and Roraima) (Figure 1). The Guiana Shield is located between $3^{\circ} \mathrm{S}$ and $10^{\circ} \mathrm{N}$ and $63^{\circ} \mathrm{W}$ and $48^{\circ} \mathrm{W}$ and is a low population density area covering 2.3 million $\mathrm{km}^{2}$ [26]. It is covered entirely by the Amazon rainforest. This area is located near the equator and is subjected to high cloud cover as part of a regular and important cycle of evaporation and precipitation due to the Intertropical Convergence Zone (ICTZ) or monsoon trough. The ICTZ passes twice over the Guiana Shield, causing heavy rainfall and defining two main seasons: the dry season from July to October, when the ICTZ is located north of the Guiana Shield and the sky is mostly clear, and the rainy season from November to June.

\subsection{Satellite data}

The satellite images used in this study comes from the meteorological geostationary satellite GOES-13, orbiting at $74.5^{\circ} \mathrm{W}$. Images are from the visible channel $(0.55 \mu \mathrm{m}-0.75$ $\mu \mathrm{m})$ and are taken every 30 minutes, with a spatial resolution of $1 \mathrm{~km}$ in latitude and $0.6 \mathrm{~km}$ in longitude, with a ground spot of approximately $1 \mathrm{~km}$ in diameter. The selected images are from April 27th 2010 to July 15th 2015 (5 and a half years) and were provided by the 
Comprehensive Large Array-data Stewardship System (CLASS) catalogue. We divided the day into hourly slots, as suggested by Rigollier [27]. The period of the day for this study lasts from slot 18 (8h45 GMT) to slot 46 (22h45 GMT). Satellite data related to ground elevation were also used in this study. The elevation map is obtained from the Shuttle Radar Topography Mission (SRTM) digital elevation model downloaded at a resolution of $90 \mathrm{~m}$ [28]. Figure 1 shows the ground elevation map of the study zone.

Data from the radiation datasets of Meteosat Second Generation solar radiation products, provided by Satellite Application Facility on Climate Monitoring (CM-SAF) were also used in this study. The selected product is named Surface Solar RAdiation data set Heliosat (SARAH), it spans the period from 1983 to 2013 with a spatial resolution of $0.05^{\circ} \times 0.05^{\circ}$ and covers the region $\pm 65^{\circ}$ in latitude and $\pm 65^{\circ}$ in longitude. A detailed description of the data by the CM-SAF can be found in Ref. [29, 30].The variables used from this dataset are the hourly Surface Incoming Shortwave Irradiance (SIS) and hourly Direct Normal Irradiance (DNI). SIS is usually also called global horizontal irradiance (GHI) or solar surface irradiance (SIS) [30]. It is expressed in W. $\mathrm{m}^{-2}$. Only days in which measured GHI by pyranometers and estimated GHI from SARAH and optimized Heliosat2 datasets overlapped were considered. This period runs from 27th April 2010 to 31th December 2013 except 17 days between 1st and 17th October 2010 which have been discarded due to apparently poor SARAH dataset quality over the area of interest.

\subsection{In situ data}

Very few stations measuring solar irradiation have been established in the Guiana Shield and they have very sparse coverage. Measurements of global irradiation used in this study are from six ground stations located in French Guiana and managed by the French national meteorological agency (Meteo France). The list of the stations and their latitude, longitude, and altitude are given in Table 1.

Table 1. Latitude, longitude, and altitude of ground meteorological stations in French Guiana

\begin{tabular}{llll} 
Station & Latitude $\left[{ }^{\circ} \mathrm{N}\right]$ & Longitude $\left[{ }^{\circ} \mathrm{E}\right]$ & Altitude $[\mathrm{m}]$ \\
\hline Saint Georges & 3.89 & -51.80 & 6 \\
Rochambeau & 4.82 & -52.37 & 4 \\
Kourou & 5.21 & -52.75 & 12 \\
Ile Royale & 5.28 & -52.58 & 48 \\
Saint Laurent & 5.49 & -54.03 & 4 \\
Maripasoula & 3.64 & -54.03 & 104
\end{tabular}

There are not, to our knowledge, global solar irradiation ground stations in Guyana and Suriname. In Venezuela, although there are global irradiation ground stations [31], we did not have access to these data. Ground stations in French Guiana are equipped with Kipp and Zonen pyranometers of type CM6B and CMP11, considered as having an accuracy of up to 3 $\%$ by the WMO [32]. Preventive maintenance of these pyranometers is carried out every two months and they are calibrated in the Radiometry National Center of Meteo France located in Carpentras, France. Standard exchange of the pyranometers is systematically carried out every two years. All of the in situ stations are located in flat or low relief areas and are not subject to 
shadow effects. As only global irradiation was available from the in-situ measurements, we performed a quality check process based on extreme values, following the method proposed by Geiger et al. [33] and the SoDa website [34]. Hourly global irradiation (Gh, in Wh.m ${ }^{-2}$ ) was considered valid when it respected the following condition:

$$
\text { 0.03. } G h_{T O A}<G h<\min \left(\left(1.2 \cdot I_{0}\right),\left(\left(1.5 \cdot I_{0} \cdot \cos \left(\theta_{s}\right) \cdot 1.2\right)+100\right)\right)
$$

where $G h_{T O A}$ is the top of atmosphere hourly irradiance, $\theta_{s}$ is the sun zenith angle, and $I_{0}$ is the solar constant $\left(1367 \mathrm{~W} \cdot \mathrm{m}^{-2}\right)$. The localization of the ground stations is shown in Figure 1.

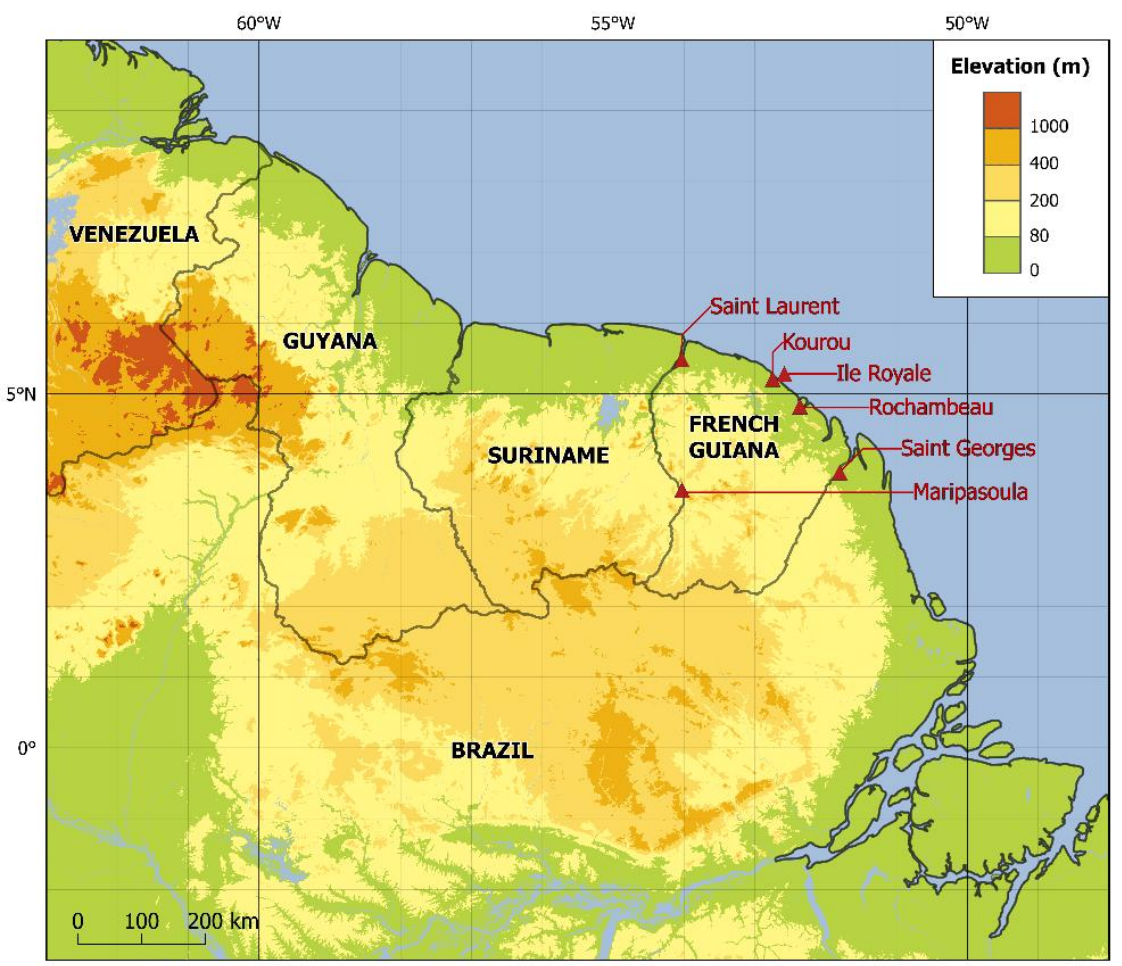

Figure 1. Elevation map (from Shuttle Radar Topography Mission SRTM)

\section{Methods}

\subsection{Optimized Heliosat-2 method}

The Heliosat-2 method [7,28] was developed in MINES Paris Tech. The principle of the method is that variation in the cloud cover above a pixel from a satellite image leads to a variation in the albedo of that pixel. This variable albedo influences the solar irradiance of the pixel. The method makes it possible to convert the reflectance of a pixel in an image from the meteorological satellite METEOSAT into values of solar irradiation. In order to determine the potential related to solar irradiation in the Guiana Shield, we used the optimized Heliosat-2 method, developed by Albarelo et al. [9], but with some changes. The optimized Heliosat-2 method can be run with images from the meteorological satellite GOES (for more details see [9]). The GOES satellite images were downloaded in the AREA format encoded in 16 bits and then transformed into digital counts $C N_{10}$ encoded in 10 bits. This operation was 
performed by moving 3 bits to the right. Once converted from 16 bits to 10 bits, the data was calibrated into radiance values.

The optimized method uses the following calibration formula provided by the National Aeronautics and Space Administration (NASA) [36], because it offers the advantage of correcting the sensor drift on a daily basis:

$$
L=\left(g_{2} \cdot d^{2}+g_{1} \cdot d+g_{0}\right) *\left(C N_{10^{-}} C N_{0}\right)
$$

where $L$ is the radiance (W. $\mathrm{m}^{-2} \cdot \mathrm{sr}^{-1} \cdot \mu \mathrm{m}^{-1}$ ), $g 0$ is the initial gain, $g 1$ and $g 2$ are the first and second order polynomial terms of the gain trend, respectively, $d$ is the number of days since the launch, $C N 1 O$ is the 10-bit digital count, and $C N O$ is an offset (equal to 29 for the GOES imager). Radiance was then converted into reflectance by:

$$
\rho_{\text {sat }}=\frac{L_{\lambda}}{E_{0 \_s a t} \cdot \varepsilon \cdot \cos \left(\theta_{s}\right)}
$$

where $\rho_{\text {sat }}$ is the satellite-derived reflectance or apparent reflectance, $L_{\lambda}$ is the satellite-derived radiance $\left(\mathrm{W} . \mathrm{m}^{-2} \cdot \mathrm{sr}^{-1} \cdot \mu \mathrm{m}^{-1}\right), E_{0 \_s a t}$ is the solar constant in the visible channel for the studied sensors $\left(\mathrm{W} \cdot \mathrm{m}^{-2} \cdot \mathrm{sr}^{-1} \cdot \mu \mathrm{m}^{-1}\right), \varepsilon$ is the Earth-Sun distance correction factor, and $\theta_{s}$ is the sun zenith angle (radians). The satellite reflectance was then converted into apparent reflectance by accounting for the atmospheric effects:

$\rho=\frac{\rho_{\text {sat }}-\rho_{a t m}\left(\theta_{s}, \theta_{v}, \psi\right)}{T\left(\theta_{s}\right) T\left(\theta_{v}\right)}$

where $\rho$ is the apparent reflectance or apparent albedo, $\rho_{\text {sat }}$ is the satellite-derived reflectance, $\rho_{\mathrm{atm}}$ is the apparent reflectance of the atmosphere, $T\left(\theta_{s}\right)$ is the downward transmittance, $T\left(\theta_{v}\right)$ is the upward transmittance, $\theta_{\mathrm{s}}$ is the sun zenith angle (radians), $\theta_{v}$ is the satellite viewing angle (radians), and $\psi$ is the difference between the sun and satellite azimuthal angles. From the apparent albedo, a cloud index (n) $[9,35]$ was calculated to determine the cloud cover over a pixel:

$$
n=\frac{\rho-\rho_{g}}{\rho_{c}-\rho_{g}}
$$

where $\rho_{g}$ and $\rho_{\mathrm{c}}$ are the ground albedo and the cloud albedo, respectively. The ground albedo $\left(\rho_{g}\right)$ was selected, for each pixel, as the second minimum detected on a sliding time window of 61 days by considering all of the slots where the solar elevation angle is higher than $40^{\circ}$. The size of the time window was significant but it is explained by a weak annual evolution of the ground albedo because of the weak phenology of the vegetation and the absence of snowfall.

Regarding the calculation of the cloud albedo, unlike Albarelo et al. [14] we did not retain the maximum value of pixel reflectance for the whole zone. Instead, because of the size of the study site (ten times bigger than French Guiana, therefore the slot when the sun is 
directly overhead is not the same everywhere) and calculation time, we kept the original formula suggested by Rigollier et al. [10] (equation 6):

$$
\begin{aligned}
& \rho_{c}=\frac{\rho_{\text {eff }}-\rho_{\text {atm }}\left(\theta_{s}, \theta_{v}, \psi\right)}{T\left(\theta_{s}\right) T\left(\theta_{v}\right)} \\
& \rho_{\text {eff }}=0.85-0.13\left\lfloor 1-e^{-4\left(\cos \left(\theta_{s}\right)\right)^{5}}\right]
\end{aligned}
$$

where $\rho_{\text {eff }}$ is the effective cloud albedo. This formula was applied to every pixel and at every slot. From the cloud index, we calculated the clear sky index $K c$ [37-38]:

$$
\begin{array}{ll}
n \leq-0.2 & K c=1.2 \\
-0.2<n \leq 0.8 & K c=1-n \\
0.8<n \leq 1.1 & K c=2.0667-3.6667 n+1.6667 n^{2} \\
1.1<n & K c=0.05
\end{array}
$$

Assessment of the global horizontal irradiation (GHI) on the ground was obtained by combining the clear-sky index $(K c)$ [39] and the clear-sky irradiation $\left(G_{c h}\right)$ using the following equation (9):

$$
G H I=K c * G_{c h}
$$

The clear-sky irradiation $\left(\mathrm{Wh} \cdot \mathrm{m}^{-2}\right.$ ) is the irradiation on the ground in the case of a cloudless sky, only attenuated by aerosols and gases. We derived it using the ESRA model [27] in which attenuations by aerosols and gases (scattering by aerosols, absorption by gases) are modeled using the Linke turbidity factor $\left(T_{L}\right)$. Climatological values of $T_{L}$, calculated over 20 years $(1983$ - 2003), were obtained via the SoDa website as a monthly set of values. The methodology used to obtain these values has been published by [40]. Monthly values were temporally and linearly interpolated in order to obtain daily values. For the selected window concerning the Guiana Shield, the Linke turbidity factor is equal to 4.1 on average, corresponding to a hot and moist air, and varies between 2.9 in the dry season and 6.1 in the wet season. We did not adopt a fixed Linke turbidity factor, as was the case in Albarelo et al. [14], because of the extent of the study zone and the variability of $T_{L}$ across different zones. To obtain the direct normal irradiation (DNI), we used the following formulas:

$$
G_{c h}=D_{c h}+B_{c h}
$$

where $D_{c h}$ is the diffuse clear sky irradiation $\left(\mathrm{Wh} \cdot \mathrm{m}^{-2}\right.$ ) and $B_{c h}$ is the direct clear sky irradiation $\left(\right.$ Wh. $\mathrm{m}^{-2}$ ). Then, the following equation was used:

$$
\begin{aligned}
& B H I=K c * B_{c h} \\
& D N I=B H I / \cos \left(\theta_{z}\right)
\end{aligned}
$$

where $B H I$ is the direct hourly irradiation $\left(\mathrm{Wh}^{-2} \mathrm{~m}^{-2}\right.$ and DNI is the direct irradiation normal to a surface $\left(\right.$ Wh.m $\left.{ }^{-2}\right)$. 


\section{Results and discussion}

\subsection{Validation}

We assess estimates of the optimized Heliosat- 2 method by using two types of data : in situ measurement data and SARAH solar radiation data. Validation of the GHI estimates derived from the optimized Heliosat- 2 method is first performed by comparing global irradiation measurements from six ground stations located in French Guiana. Figure 2 exhibits the scatter plots between hourly GHI estimates from optimized Heliosat2 and hourly measured GHI. In order to see if the local conditions have an impact on the skill of the model, separate scatter plots between estimated GHI and measured GHI were constructed for each station. The dotted line with a slope of one represents the ideal case, in which optimized Heliosat2 estimations would be identical to the measured data. The full line represents the least-square fitting line. GHI comprise a large variety of hourly irradiation, the dots cover a

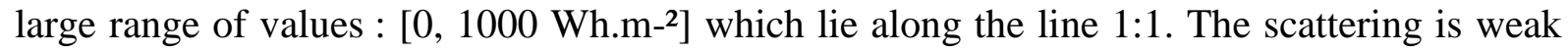
indicating that the optimized Heliosat-2 method reproduces well the GHI. Scatter plots are similar for stations near the ocean and for inland stations. We note, however, a small overestimation for low irradiation values as seen by a high density of dots above the ideal regression line (dotted line in Figure 2). Nevertheless, the effect of this overestimation is limited because of its small contribution to the daily irradiation. Statistical indices RMSE, Bias and correlation coefficient for each station are summarized in Table 2. The statistical errors calculated on these six stations agree with the results obtained from the Heliosat-2 method for other geographical zones [41-45]. The correlation coefficient (CC) varies between 0.92 and 0.95 (Table 2). The day-to-day variations are well represented by the optimized Heliosat 2 data for all sites The relative MBE and the relative RMSE are normalized by their mean values. RMSE values are around $18 \%$ and biases are close to $1 \%$ for all stations. The method produces good results in estimating hourly GHI for all stations regardless of their geographical location.

Table 2. Comparison between hourly GHI from optimized Heliosat-2 and hourly measured GHI (in Wh. $\mathrm{m}^{-2}$ ) for 2010-2013 period. In brackets, quantities are relative to the mean measured GHI.

\begin{tabular}{lcccc} 
Station & $\begin{array}{c}\text { Number of } \\
\text { records }\end{array}$ & CC & $\begin{array}{c}\text { RMSE } \\
\text { Wh.m }{ }^{-2}(\%)\end{array}$ & $\begin{array}{c}\text { Bias } \\
\text { Wh.m }\end{array}$ (\%) $^{-2}$ \\
\hline Saint Georges & 8995 & 0.92 & $96(20 \%)$ & $8(2 \%)$ \\
Rochambeau & 8204 & 0.92 & $98(19 \%)$ & $-1(0 \%)$ \\
Kourou & 9242 & 0.94 & $91(17 \%)$ & $7(1 \%)$ \\
Ile Royale & 8394 & 0.95 & $86(15 \%)$ & $3(1 \%)$ \\
Saint Laurent & 8657 & 0.92 & $96(19 \%)$ & $5(1 \%)$ \\
Maripasoula & 8053 & 0.92 & $94(18 \%)$ & $-1(0 \%)$ \\
All Stations & 51545 & 0.93 & $94(18 \%)$ & $4(1 \%)$
\end{tabular}




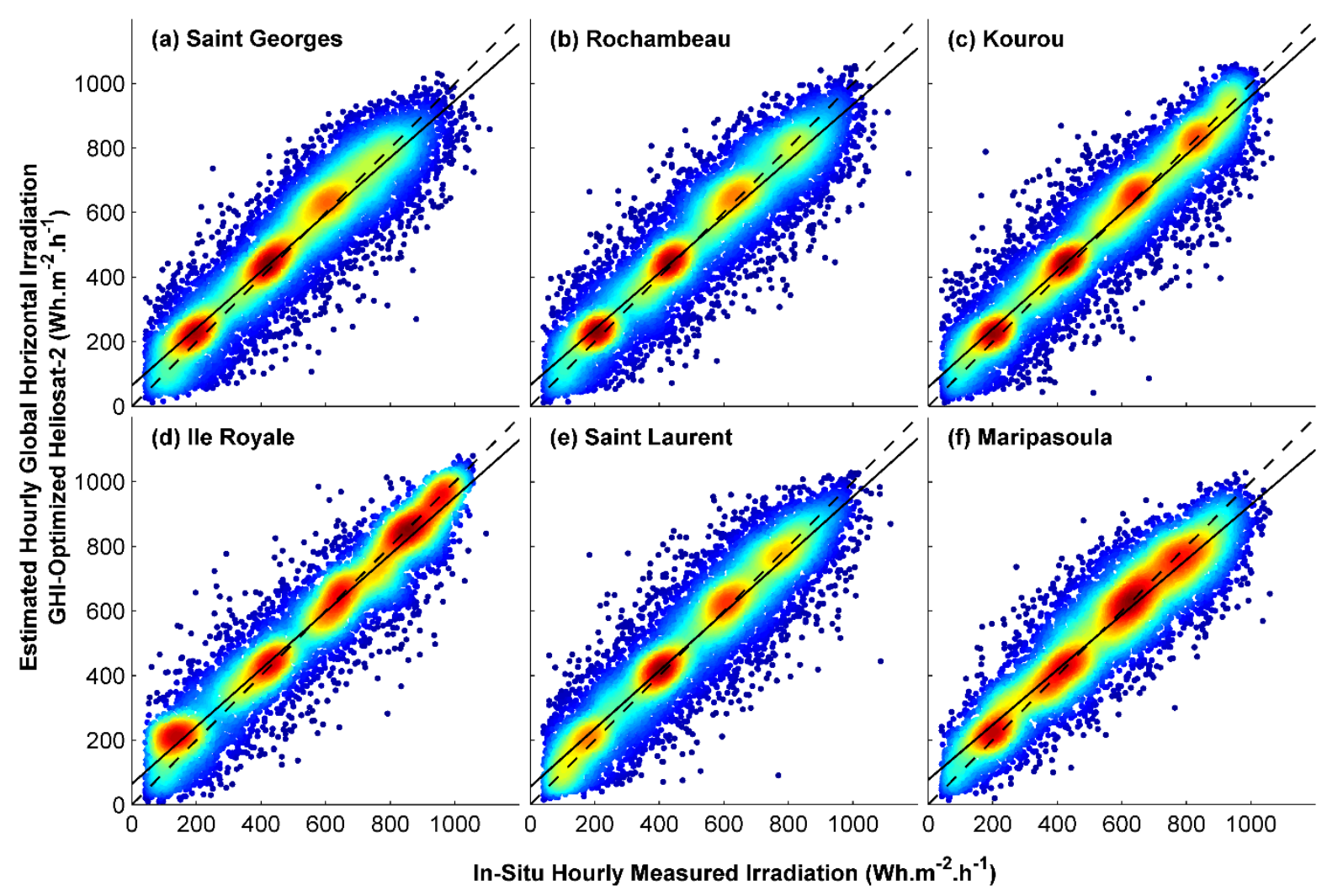

Figure 2. Comparison between hourly GHI from optimized Heliosat2 and hourly measured GHI for the 2010-2013 period for the 6 stations in French Guiana.

Solar radiation estimates from the optimized Heliosat-2 method were thoroughly compared with solar radiation estimates from SARAH database [29, 30]. First we evaluated the accuracy of the SARAH data by comparing the SIS-SARAH estimates with GHI measurements using statistical methods. Table 3. summarizes statistical errors between SIS-SARAH estimates and in situ GHI measurements. Comparatively to Table 2, the overall bias increases by $16 \mathrm{Wh} / \mathrm{m}^{2}$ (3\%) indicating that SIS-SARAH overestimates the GHI. The overall RMSE increases by 37 $\mathrm{Wh} / \mathrm{m}^{2}(7 \%)$. The correlation coefficient drops to an overall value of 0.88 . Figure 3 exhibits the scatter plots between hourly SIS-SARAH estimates and hourly measured GHI for each station. The dots are scattered over the regression line which may explain the lower value of the correlation coefficient and the overestimation of the SIS-SARAH. The scatter plots show that the GHI estimates from SARAH is less accurate than GHI estimates from optimized Heliosat-2. The discrepancies in performances of the SIS-SARAH estimates are probably due to the longitude of the Meteosat satellite $\left(0^{\circ}\right)$ with respect to the eccentric position of the stations that may contribute to the bias uncertainty because what the satellite sees is not exactly what is happening in the atmospheric column right above a station. Albarelo et al. [14] demonstrates that the satellite viewing angle has an impact on the accuracy of the estimates: the smaller the satellite viewing angle, the better the accuracy of the estimates. Given the location of the stations the deviation of the GOES-East satellite is lower than that of the Meteosat satellite. It can be concluded that the GHI optimized Heliosat-2 estimates provide best accuracy compared with SIS-SARAH estimates in estimating hourly global solar irradiance. 
Table 3. Comparison between hourly estimates from SIS-SARAH and hourly measured GHI (in Wh. $\mathrm{m}^{-2}$ ) for the 2010-2013 period. In brackets, quantities are relative to the mean measured GHI.

365

\begin{tabular}{lcccccc}
\multicolumn{1}{c}{ Station } & $\begin{array}{c}\text { Number of } \\
\text { records }\end{array}$ & Slope & $\begin{array}{c}\text { Interception } \\
\text { Wh.m }\end{array}$ & CC & $\begin{array}{c}\text { RMSE } \\
\text { Wh.m } \text { - }^{-2}(\%)\end{array}$ & $\begin{array}{c}\text { Bias } \\
\text { Wh.m }\end{array}$ (2) $\left.^{-2}\right)$ \\
\hline Saint Georges & 8995 & 0.89 & 97 & 0.85 & $143(30 \%)$ & $45(9 \%)$ \\
Rochambeau & 8204 & 0.88 & 89 & 0.86 & $141(28 \%)$ & $30(6 \%)$ \\
Kourou & 9242 & 0.96 & 47 & 0.90 & $124(24 \%)$ & $28(5 \%)$ \\
Ile Royale & 8394 & 0.92 & 30 & 0.93 & $110(20 \%)$ & $-15(-3 \%)$ \\
Saint Laurent & 8657 & 0.89 & 67 & 0.85 & $139(28 \%)$ & $14(3 \%)$ \\
Maripasoula & 8053 & 0.91 & 66 & 0.87 & $129(24 \%)$ & $17(3 \%)$ \\
All Stations & 51545 & 0.91 & 68 & 0.88 & $131(25 \%)$ & $20(4 \%)$
\end{tabular}
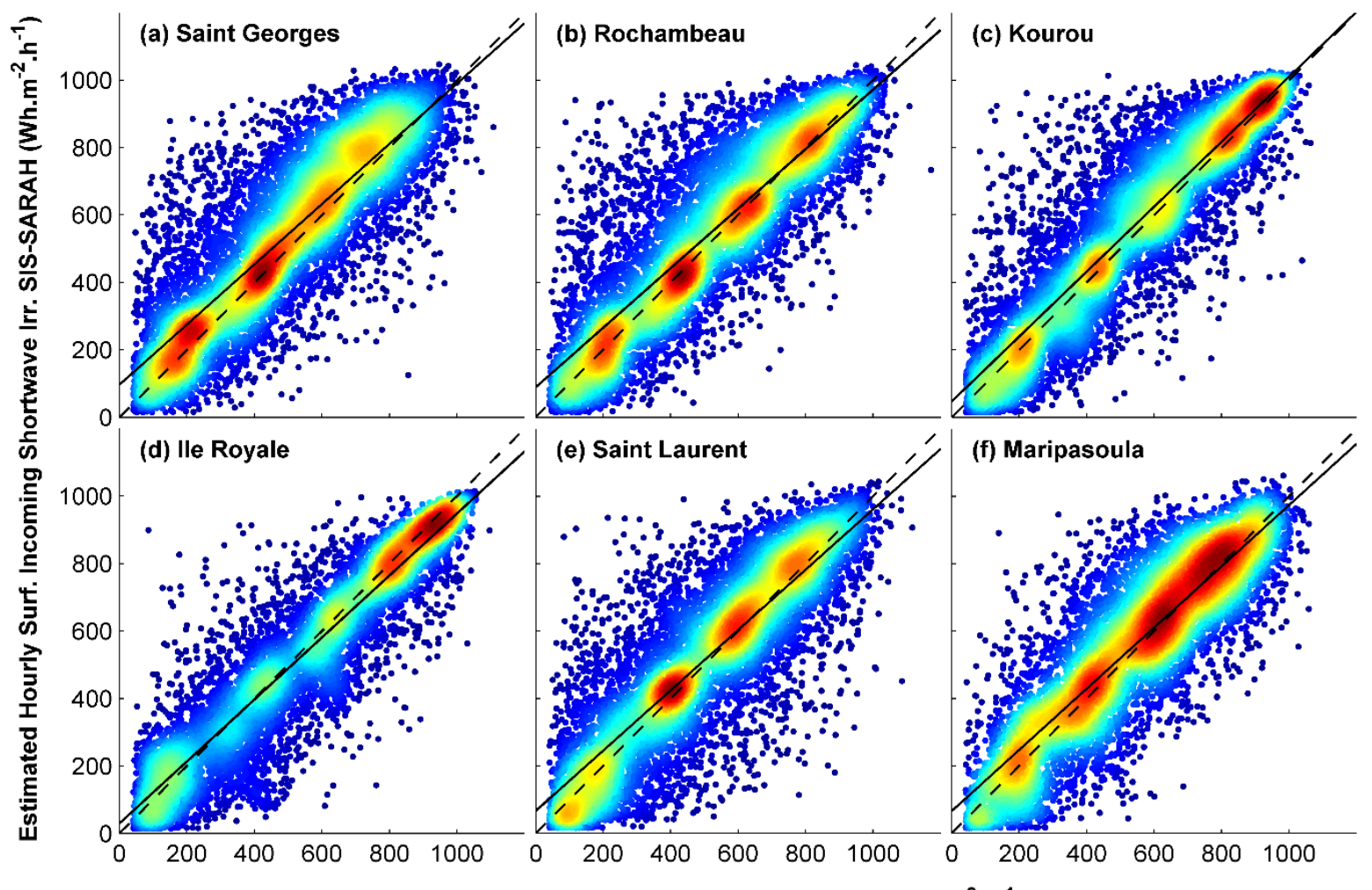

In-Situ Hourly Measured Irradiation (Wh. $\mathrm{m}^{-2} \cdot \mathrm{h}^{-1}$ )

Figure 3. Comparison between hourly estimates from SIS-Sarah and measured GHI for the 2010-2013 period for the 6 stations in French Guiana.

We also compare GHI from optimized Heliosat-2 method with SIS estimates from SARAH database. Table 4. summarizes statistical errors between GHI from optimized Heliosat-2 and SIS- SARAH. The mean bias is around $-16 \mathrm{Wh} / \mathrm{m}^{2}(-3 \%)$ and the mean RMSE is $115 \mathrm{Wh} / \mathrm{m}^{2}$ (21\%). The overall value of correlation coefficient is 0.90 . Figure 4 exhibits the scatter plots between GHI estimates from optimized Heliosat2 and SIS estimates from SARAH. The scattering is important under the regression line indicating that the GHI from optimized 
382

Table 4. Statistical errors between hourly estimates from GHI optimized Heliosat-2 and SIS-Sarah for the 2010-2013 period

\begin{tabular}{lcccccc} 
Station & $\begin{array}{c}\text { Number of } \\
\text { records }\end{array}$ & Slope & $\begin{array}{c}\text { Interception } \\
\left(\text { Wh.m }^{-2}\right)\end{array}$ & CC & $\begin{array}{c}\text { RMSE } \\
\left.\text { Wh.m } \text { (\%) }^{-2}\right)\end{array}$ & $\begin{array}{c}\text { Bias } \\
\text { Wh.m }\end{array}(\%)$ \\
\hline Saint Georges & 8995 & 0.80 & 69 & 0.88 & $127(24 \%)$ & $-37(-7 \%)$ \\
Rochambeau & 8204 & 0.80 & 76 & 0.88 & $129(24 \%)$ & $-31(-6 \%)$ \\
Kourou & 9242 & 0.83 & 75 & 0.92 & $111(20 \%)$ & $-20(-4 \%)$ \\
Ile Royale & 8394 & 0.87 & 88 & 0.93 & $108(20 \%)$ & $18(3 \%)$ \\
Saint Laurent & 8657 & 0.84 & 73 & 0.90 & $113(22 \%)$ & $-9(-2 \%)$ \\
Maripasoula & 8053 & 0.82 & 80 & 0.93 & $98(18 \%)$ & $-18(-3 \%)$ \\
All Stations & 51545 & 0.83 & 75 & 0.90 & $115(21 \%)$ & $-16(-3 \%)$
\end{tabular}

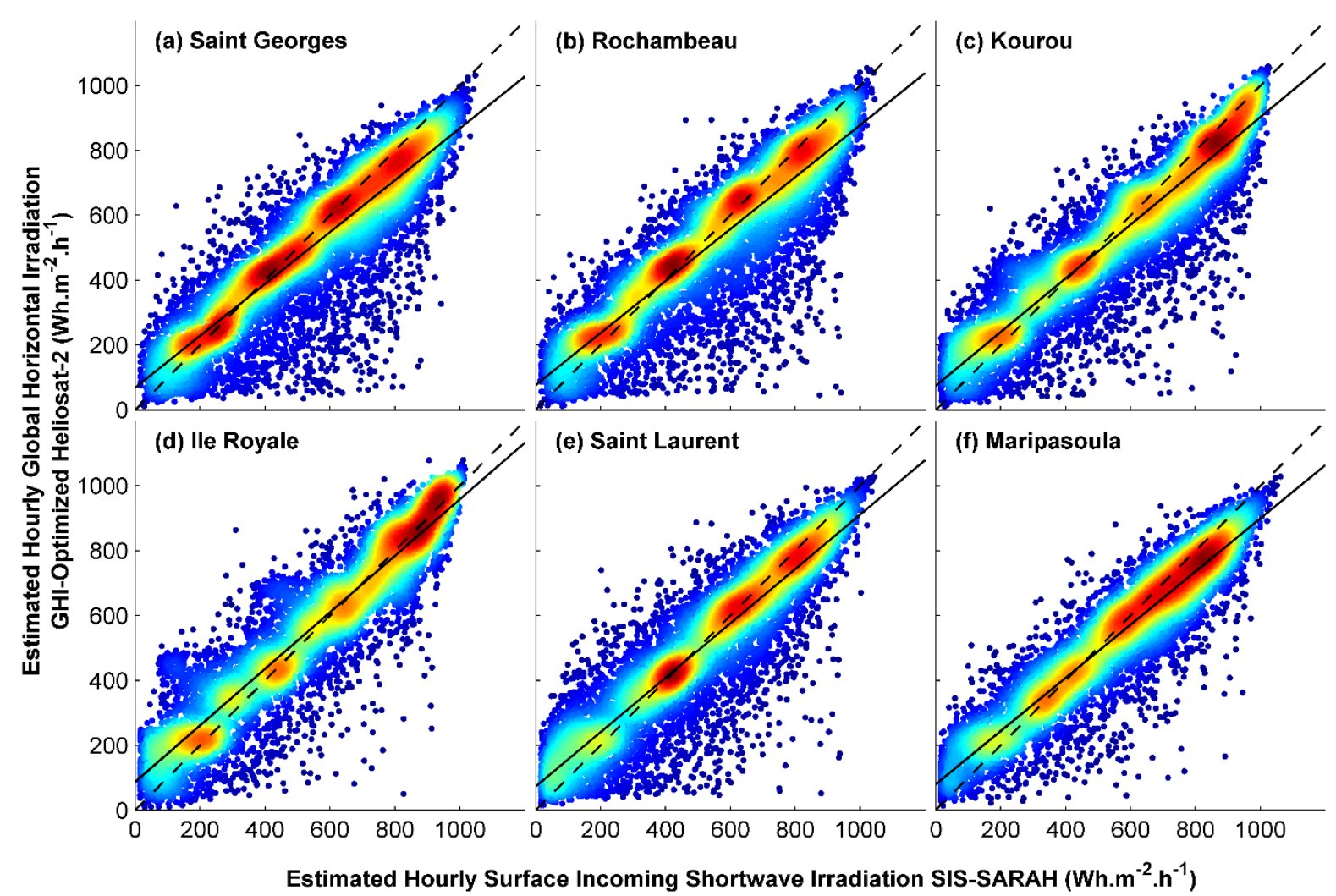

Figure 4. Comparison between hourly estimates from GHI optimized Heliosat-2 and SIS-Sarah for the 2010-2013 period and for the 6 stations in French Guiana.

Since no measurements of DNI are available, we compare DNI estimates from SARAH database and DNI from optimized Heliosat-2 method. Table 5 summarizes statistical errors between DNI- SARAH estimates and DNI estimates from optimized Heliosat-2. The mean bias is around $-5 \mathrm{Wh} / \mathrm{m}^{2}(-1 \%)$ and the mean RMSE is $180 \mathrm{Wh} / \mathrm{m}^{2}(42 \%)$. The overall value of correlation coefficient is 0.76. Again, DNI from optimized Heliosat-2 is underestimated comparatively to the SIS-SARAH data. Since SARAH data tends to overestimate solar radiation, it can be concluded that the Heliosat-2 estimates are relevant and correctly reproduce the solar radiation values. 
Table 5. Statistical errors between hourly estimates from DNI-optimized Heliosat-2 and DNI-Sarah for the 2010-2013 period for the 6 stations in French Guiana.

\begin{tabular}{lllll} 
Station & $\begin{array}{l}\text { Number of } \\
\text { records }\end{array}$ & CC & $\begin{array}{l}\text { RMSE in } \\
\text { Wh.m } \text { - }^{-2}(\%)\end{array}$ & $\begin{array}{l}\text { Bias in } \\
\text { Wh.m }\end{array}$ \\
\hline Saint Georges & 8995 & 0.70 & $181(44 \%)$ & $-13(-3 \%)$ \\
Rochambeau & 8204 & 0.72 & $187(43 \%)$ & $-13(-3 \%)$ \\
Kourou & 9242 & 0.82 & $175(37 \%)$ & $-37(-8 \%)$ \\
Ile Royale & 8394 & 0.79 & $187(40 \%)$ & $-8(-2 \%)$ \\
Saint Laurent & 8657 & 0.72 & $186(49 \%)$ & $28(7 \%)$ \\
Maripasoula & 8053 & 0.75 & $165(41 \%)$ & $18(5 \%)$ \\
All Stations & 51545 & 0.76 & $180(42 \%)$ & $-5(-1 \%)$
\end{tabular}

\subsection{Global and direct irradiation potential}

Figure 5 is a map of the daily average GHI from 2010 to 2015 . For the whole study area, GHI daily average values vary from 4.46 to $5.48 \mathrm{kWh} \cdot \mathrm{m}^{-2}$.day ${ }^{-1}$. Zones showing the best global solar potential are mostly coastal zones up to a distance of 5 to $10 \mathrm{~km}$ from the coastline. Here, we find an irradiation potential 8 to $12 \%$ higher than the mean value of global irradiation. This can be explained by the specific wind system and the sea breeze phenomenon that diminishes diurnal clouds in coastal zones [46]. This phenomenon is also observed at the mouths of rivers. Zones located west of stretches of water also show 10 $\%$ higher GHI. Four zones can be distinguished with a potential greater than $5 \mathrm{kWh} . \mathrm{m}^{-2} \cdot \mathrm{day}^{-1}$ : east Venezuela, the Venezuela/Guyana/Brazil border, the central strip of Suriname, and north Brazil.
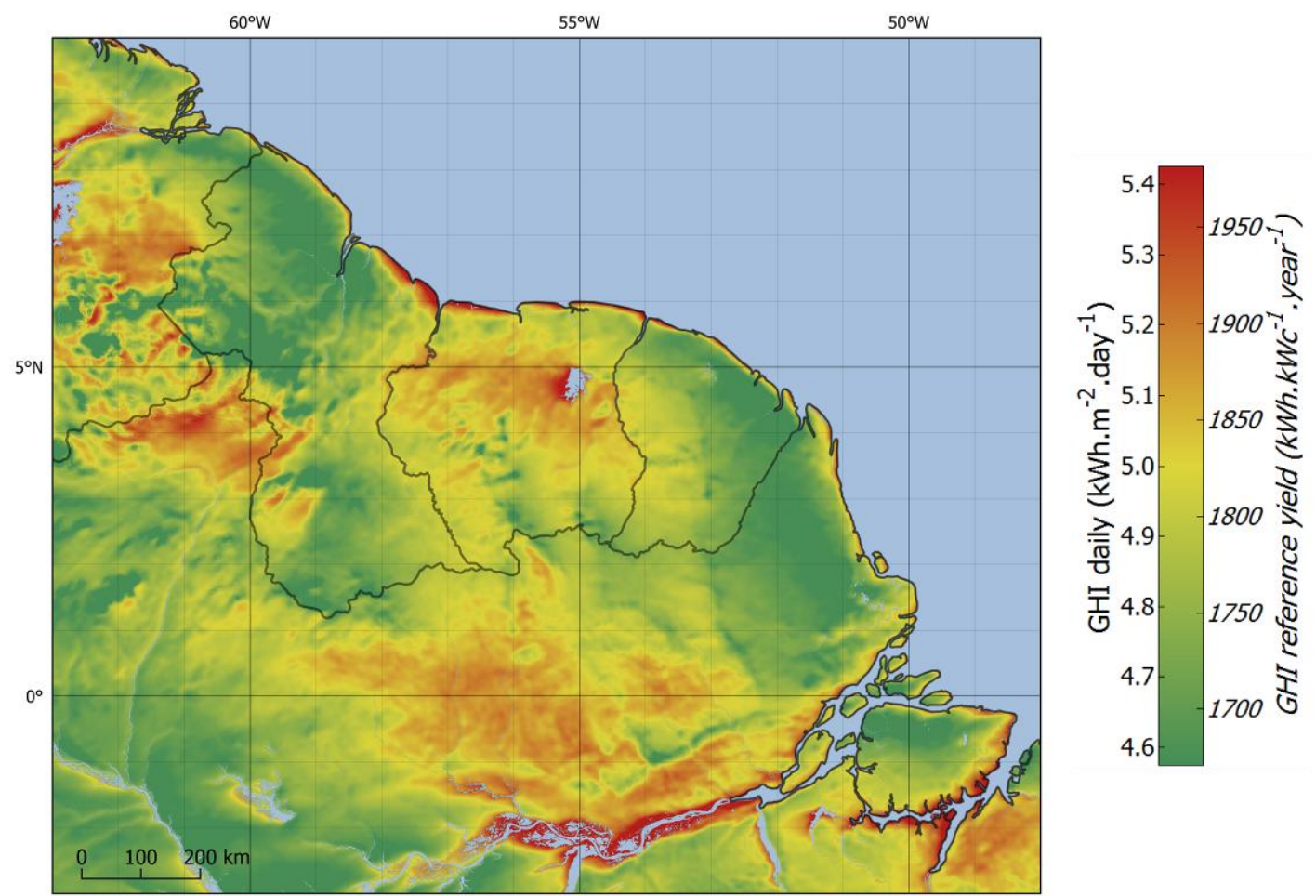

Figure 5. Map of the annually averaged daily global irradiation (GHI) and the annual reference yield for photovoltaic energy production 
For most of the study zone, results show that the range of GHI values on the Guiana Shield (between 4.2 and $5.6 \mathrm{kWh} \cdot \mathrm{m}^{-2}$. day ${ }^{-1}$ ) agree with the range of GHI values in tropical regions published in other studies. This solar energy potential is nearly three times higher than in countries of the European Union [19], where initiatives towards solar energy are more widespread [47-49]. However, if we compare the average solar potential in the Guiana Shield $\left(4.91 \mathrm{kWh} . \mathrm{m}^{-2} \cdot\right.$ day $\left.^{-1}\right)$ to that of other studies conducted in tropical zones, for example, we notice that it is slightly lower. Indeed, the average GHI of the whole Guiana Shield is lower than in Myanmar and in Cambodia, where it is approximately $5.1 \mathrm{kWh} \cdot \mathrm{m}^{-2} \cdot \mathrm{day}^{-1}$ [15-16], as well as in Djibouti (5.92 kWh.m ${ }^{-2}$.day ${ }^{-1}$ ) [50]. This is almost certainly because of the regular presence of cloud masses in the Guiana Shield due to the ITCZ.

On the other hand, the average GHI value agrees with that from Pereira et al. [19], in the framework of the SWERA (Solar and Wind Energy Resources Assessment) project that resulted in the creation of the Brazilian Solar Energy Atlas. The GHI reported in the Atlas is equal to $5.5 \mathrm{kWh} \cdot \mathrm{m}^{-2}$ with a bias of $7 \%\left(353.48 \mathrm{Wh} \cdot \mathrm{m}^{-2}\right)$ and a RMSE of $15 \%(640.29$ Wh. $\mathrm{m}^{-2}$ ). This average potential corresponds to the GHI values in Figure 5. Figure 5 also shows the spatial distribution of the annual average potential production of photovoltaic energy. The second scale of the map (annual reference yield) indicates the theoretical number of hours in the year that a photovoltaic system would run at maximum efficiency. The higher this indicator is, the higher the production of photovoltaic energy. This indicator is especially useful because it allows refining of the size of photovoltaic facilities as a function of the location and the amount of energy required. In terms of GHI, production potential is highest in the north of Brazil, Suriname, and Venezuela. On average, the production potential of photovoltaic energy of the Guiana Shield is about $1780 \mathrm{kWh} / \mathrm{kWc}_{\text {.year }}{ }^{-1}$.

Figure 6 shows the distribution of the annually averaged daily DNI on the Guiana Shield. The direct irradiation values are between 5.11 and $6.24 \mathrm{kWh} . \mathrm{m}^{-2}$.day ${ }^{-1}$. Three zones can be distinguished with a potential greater than $5.8 \mathrm{kWh} \cdot \mathrm{m}^{-2} \cdot$ day $^{-1}$ : the Venezuela/Guyana/Brazil border region, the surroundings of the Brokopondo reservoir in Suriname, and northern Brazil. The daily mean value of DNI reaches $5.64 \mathrm{kWh} . \mathrm{m}^{-2}$.day ${ }^{-1}$, which corresponds to the average DNI from the Brazilian Atlas, which reaches $5.4 \mathrm{kWh} . \mathrm{m}^{-2}$. Comparison of our estimates of GHI and DNI solar potential and the ones obtained in the framework of the SWERA project (solar Atlas of Brazil) shows that our results for the Brazilian part of the Guiana Shield agree with those obtained by other authors. 


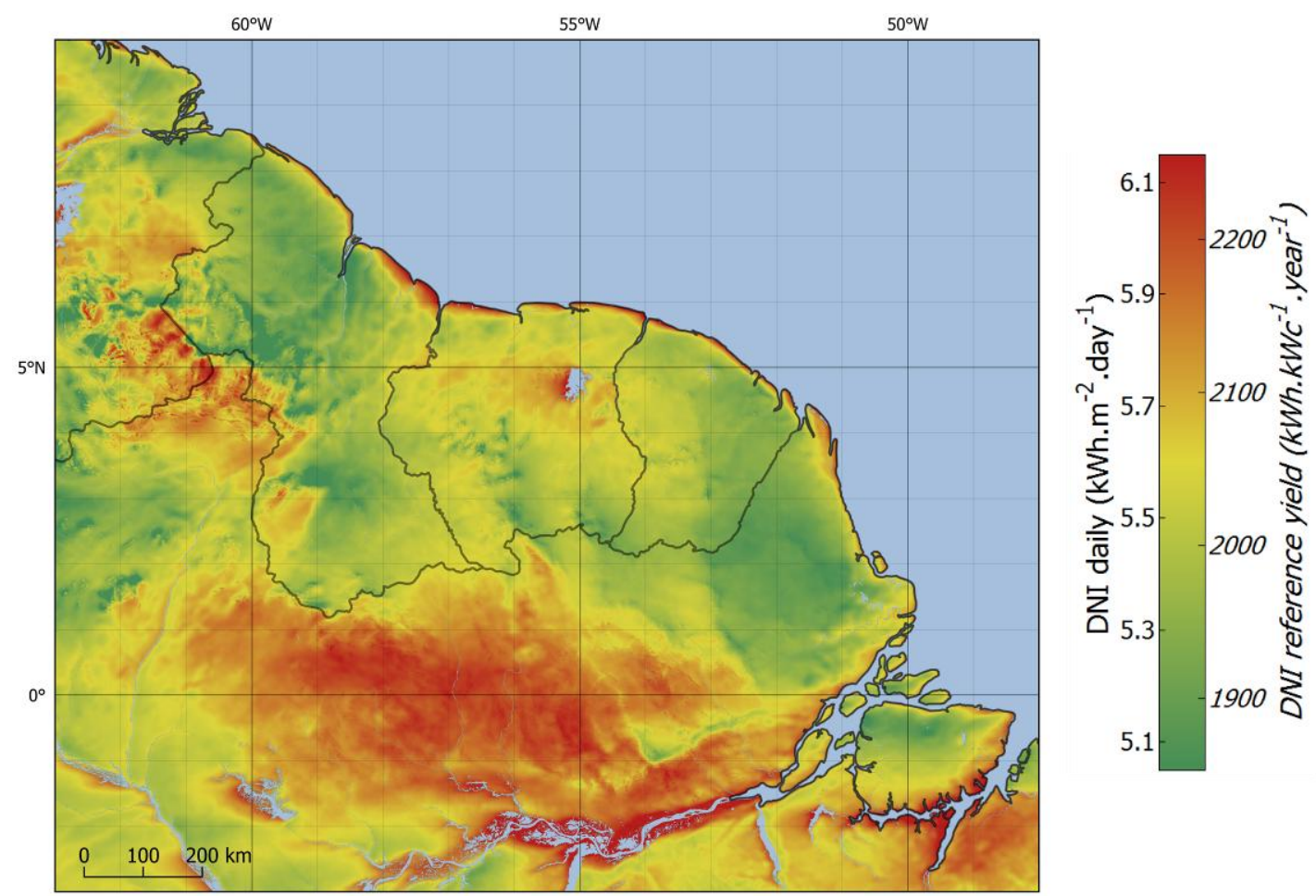

Figure 6. Map of the annually averaged daily direct normal irradiation (DNI) and the annual reference yield for photovoltaic energy production

\subsection{Spatiotemporal indicators}

This section proposes the development of innovative maps for describing land relative suitability indices for the implementation of solar energy systems (PV and CSP) over the Guiana Shield. This implementation requires knowledge of: a) areas with specific characteristics of land slope and land use, although, since remote inhabited locations are common on the Guiana Shield, land accessibility (distance from the roads and electricity transmission grid) has not been considered as a constraint; and b) solar irradiance characteristics, since weather conditions of the Guiana Shield have high spatiotemporal variability (due to the ICTZ) characterized by extreme rainfall during the wet season and partly cloudy skies during the dry season. Consideration of these two conditions is challenging but necessary for understanding their effect on solar irradiance, as well as solar energy systems.

\subsubsection{Slope indicator}

Several research studies have demonstrated that a significant slope is a limiting factor for the implementation of both PV and CSP plants [51]. Figure 7 shows a map of usable areas with a slope less than $4 \%$ (or approximately $2.29^{\circ}$ ). The threshold value of the slope is based on the work of Gherboudj \& Ghedira [20]. It is noted that land within the center of the Guiana Shield is not favorable for installation of solar plants over very large areas (several $\mathrm{km}^{2}$ ), because of the hilly nature of the area. Areas with lower relief, allowing the installation of photovoltaic plants over large areas, are located on the coast, in the border region between 
Venezuela, Guyana, the southwest part of the Guiana Shield, and in the mouth of the Amazon. These latter areas are considered suitable for the setting of both PV and CSP facilities and represent an area of $54 \%$ from the Guiana Shield total land.

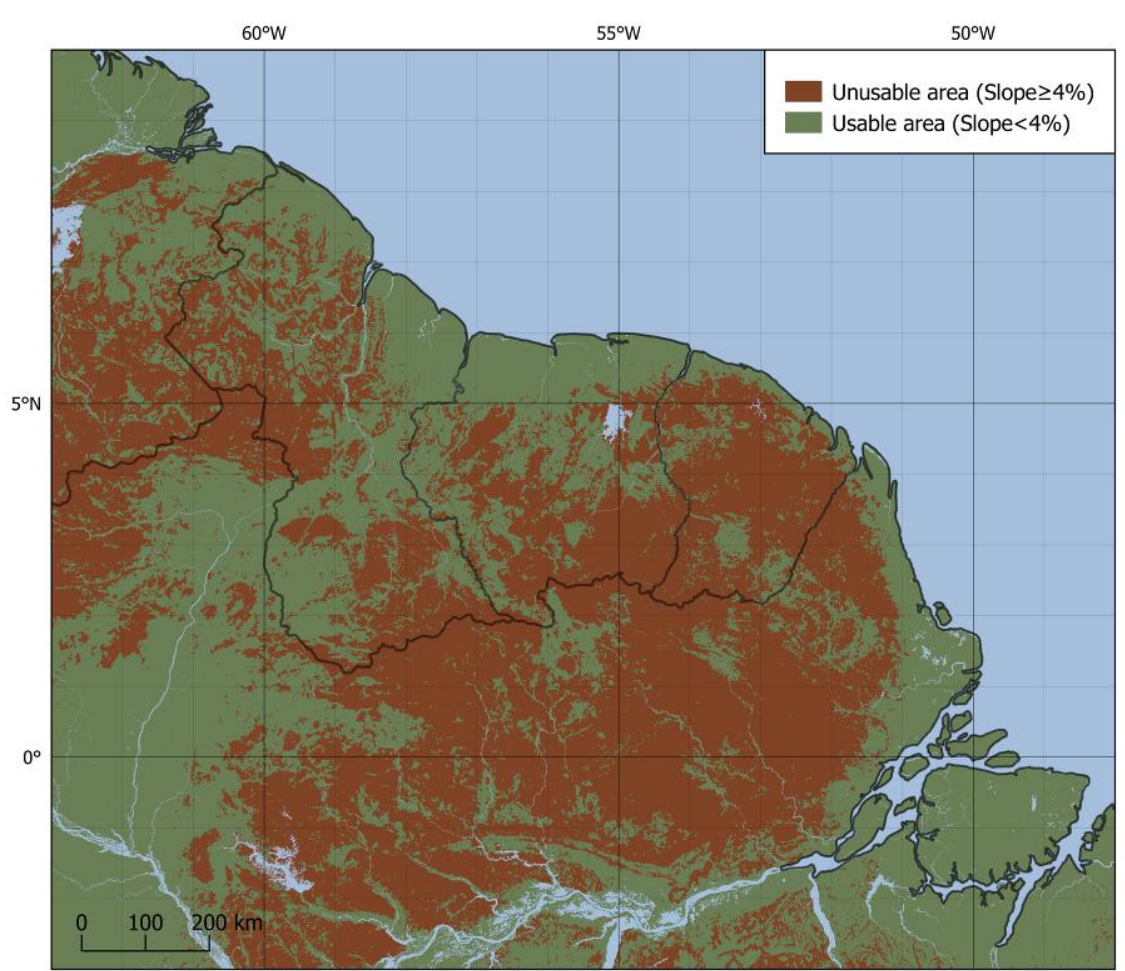

Figure 7. Map of usable areas for photovoltaic energy production

\subsubsection{Operability Indicator}

Figures 8 and 9 show the operability indicator maps. This spatial indicator represents areas where resource exploitation is sustainable, because the average annual energy potential is above a minimum threshold. This minimum level of exploitability is set to $1600 \mathrm{kWh} . \mathrm{m}^{-}$ ${ }^{2}$.year ${ }^{-1}$ for GHI [25] and $2000 \mathrm{kWh} \cdot \mathrm{m}^{-2}$.year ${ }^{-1}$ for DNI [52]. Very few areas are affected by this exclusion with regards to GHI ( $1 \%$ of the Guiana Shield total land). The areas excluded due to the DNI threshold are more important, especially in the northeast, Amapá, and across the mountainous areas on the border between Guyana and Venezuela. These areas represent an area of $31 \%$ from the Guiana Shield total land. 


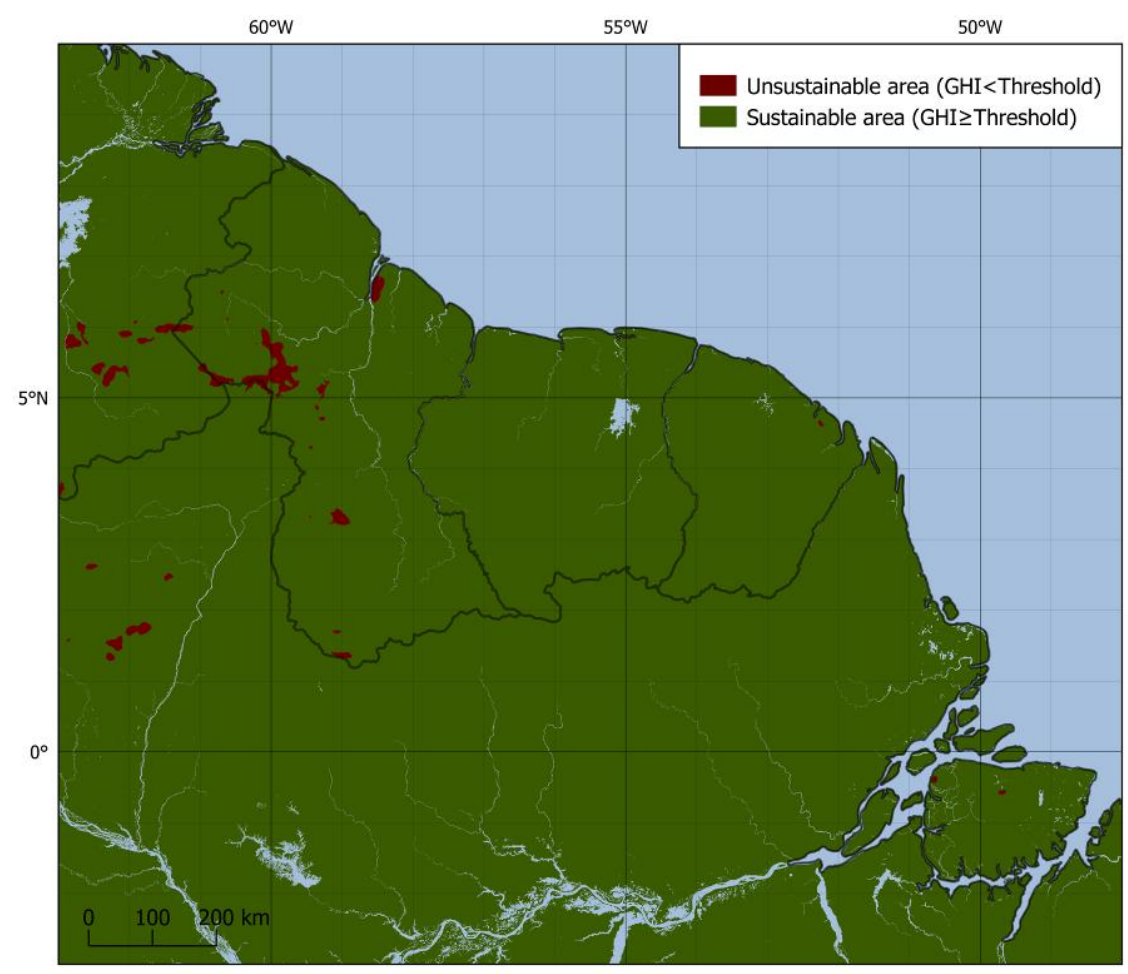

Figure 8. Map of sustainable areas for photovoltaic energy production

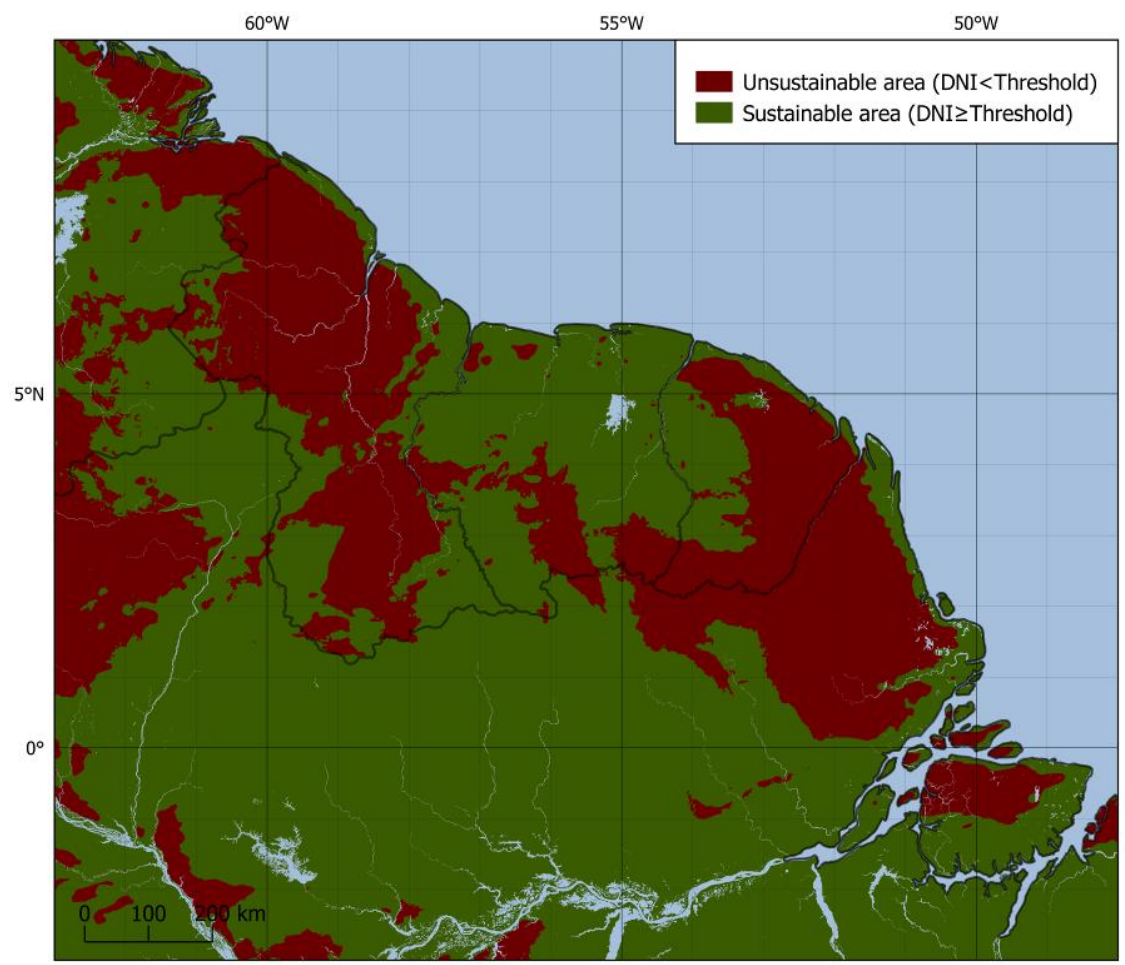

Figure 9. Map of sustainable areas for concentrator solar power energy production

\subsubsection{Suitable indicator}

Figure 10 shows the result map of combination of the slope indicator and the operability indicator. This map represents areas where solar resource exploitation is suitable 
to the terrain slope. The second limitation is due to the minimum level of exploitability described as a minimum average annual energy potential threshold under which the area is considered as unsustainable. It should be noted that areas sustainable for DNI are sustainable for GHI as well. Table 6 shows the total surface area occupied by each class of suitability. This results show that $46 \%$ of the land is unsuitable, mainly due to high terrain slope, $54 \%$ of the land is suitable of PV plants and $40 \%$ for both PV and CSP plants. Mainly, all coast areas are suitable for both PV and CSP plants, as well as the border of Amazon river and the main part of the state of Roraima in North Brazil.

\section{Table 6. Surface area of each class of suitability for photovoltaic and concentrator solar} power energy production

\begin{tabular}{|c|c|c|}
\hline Operability Class & $\begin{array}{c}\text { Surface area } \\
\left(10^{3} \mathrm{~km}^{2}\right)\end{array}$ & $\begin{array}{c}\text { Surface area } \\
(\%)\end{array}$ \\
\hline Unsuitable area & 706 & 46 \\
\hline Suitable area for PV only & 222 & 14 \\
\hline Suitable area for PV and CSP & 613 & 40 \\
\hline
\end{tabular}

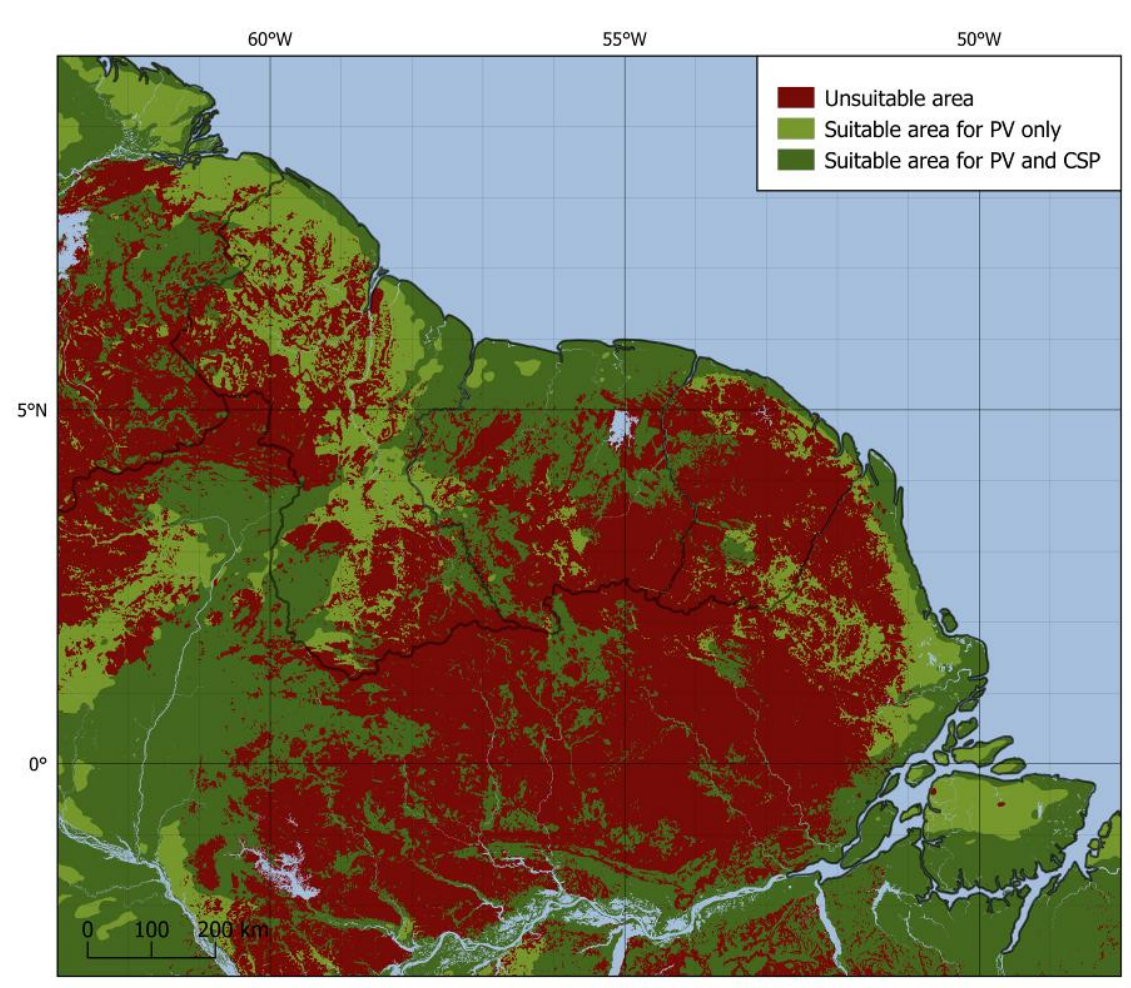

Figure 10. Map of suitable areas for photovoltaic and concentrator solar power energy production

\subsubsection{Variability indicator}

Figure 11 is a map of the inter-day GHI variability calculated for the period of 20102015. The inter-day variability was calculated as the standard deviation of daily radiation averaged over the year. Average GHI variability is $0.80 \mathrm{kWh} . \mathrm{m}^{-2}$ with a range from 0.54 to $1.20 \mathrm{kWh} . \mathrm{m}^{-2}$. Figure 12 shows the map of the average inter-day DNI variability, also 
calculated on an annual basis from 2010-2015. The values range between 0.58 and 1.58 $\mathrm{kWh} \cdot \mathrm{m}^{-2}$ with an average of $1.00 \mathrm{kWh} \cdot \mathrm{m}^{-2}$. Overall, the Guiana Shield GHI has a variability of less than $0.8 \mathrm{kWh} . \mathrm{m}^{-2}$ except in three zones: northwest Guyana, a region including northeast Suriname, French Guiana and northeast Brazil, and part of the northern region of Brazil.

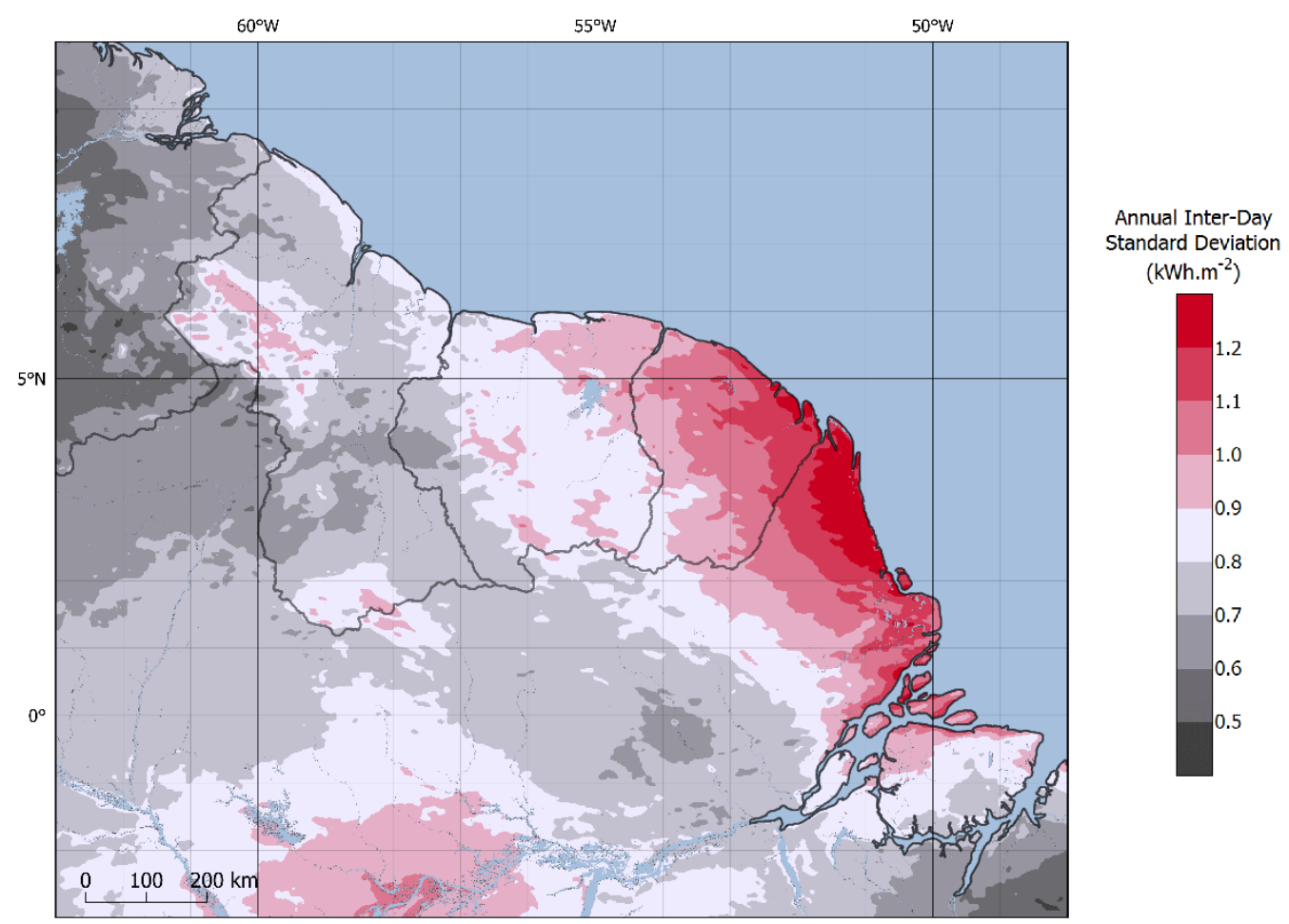

Figure 11. Map of the annual inter-day standard deviation of GHI

In the context of photovoltaic power generation, knowledge of the standard deviation of the solar potential provides information on the variability of photovoltaic electricity. Variability characterizes the intermittency of the solar resource. In order to stabilize the production of solar energy, photovoltaic plants built in areas with a high standard deviation of the solar potential will have higher energy storage requirements, and electricity production to the grid will be very unstable. Therefore, knowledge of the inter-daily standard deviation allows us to evaluate the need to integrate predictive photovoltaic systems that are connected to the network.

Indeed, when solar electricity production is anticipated, this reduces the electrical hazard for the network. The higher the standard deviation, the more prediction systems will be needed to reduce this hazard. Knowledge of inter-day standard deviation is also a support factor in the decision to install photovoltaic power plants in a given area, because the implementation strategy will differ depending on the standard deviation of solar potential. Several studies show that, in areas where the solar potential variability is high, it is best to deploy multiple small power plants instead of one large power plant (e.g., 9 plants of $1.1 \mathrm{MW}$ instead of a 10 MW plant) [53] because the "profusion effect" allows the grid to more effectively absorb solar electricity variations. 
551

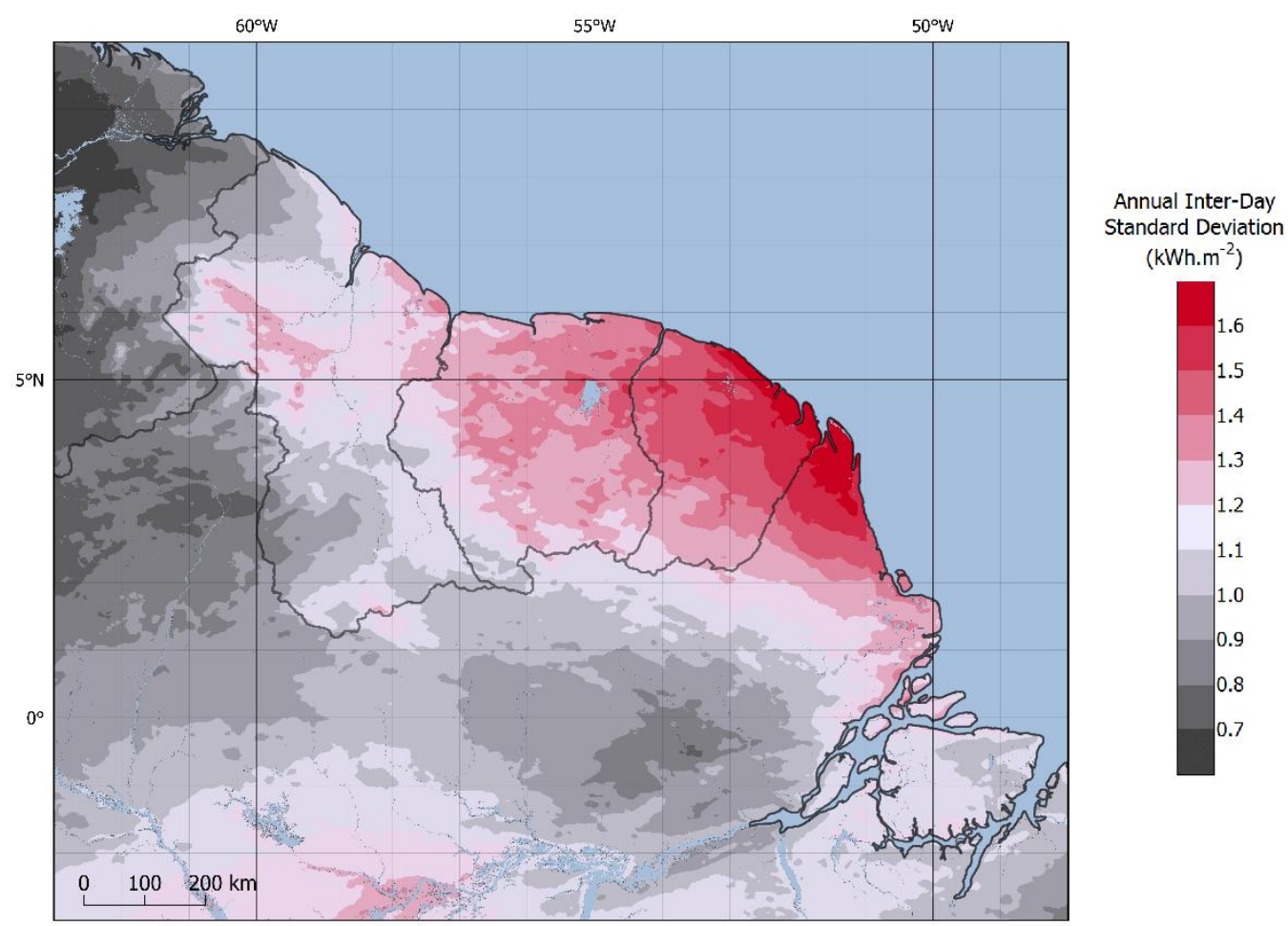

Figure 12. Map of the annual inter-day standard deviation of DNI

\subsubsection{Optimal orientation indicator}

Figure 13 shows a map of the orientation indicator, which allows for decisions regarding solar panel orientation in order to make optimal use of the solar resource. The orientation indicator was obtained by calculating the ratio between the energy received before and after solar noon (AM/PM ratio) for each pixel. This indicator represents the maximum direction of solar potential depending on the time of the day (before solar noon or after solar noon). In areas shown in green, the AM/PM ratio is greater than 1 , which corresponds to a surplus of energy receipt before solar noon, thus optimal solar resource exploitation will prioritize an eastern orientation of solar collectors (in the case of fixed orientation solar systems).

In the areas shown in brown, the AM/PM ratio is less than 0.8 , which corresponds to an energy surplus received after solar noon, therefore optimal use of the solar resource will favor an orientation towards the west. Of course, this orientation indicator only summarizes information on the most accurate optimum angle and adjusting the orientation of the solar collectors should be considered to maximize the performance of any proposed solar power plant. 


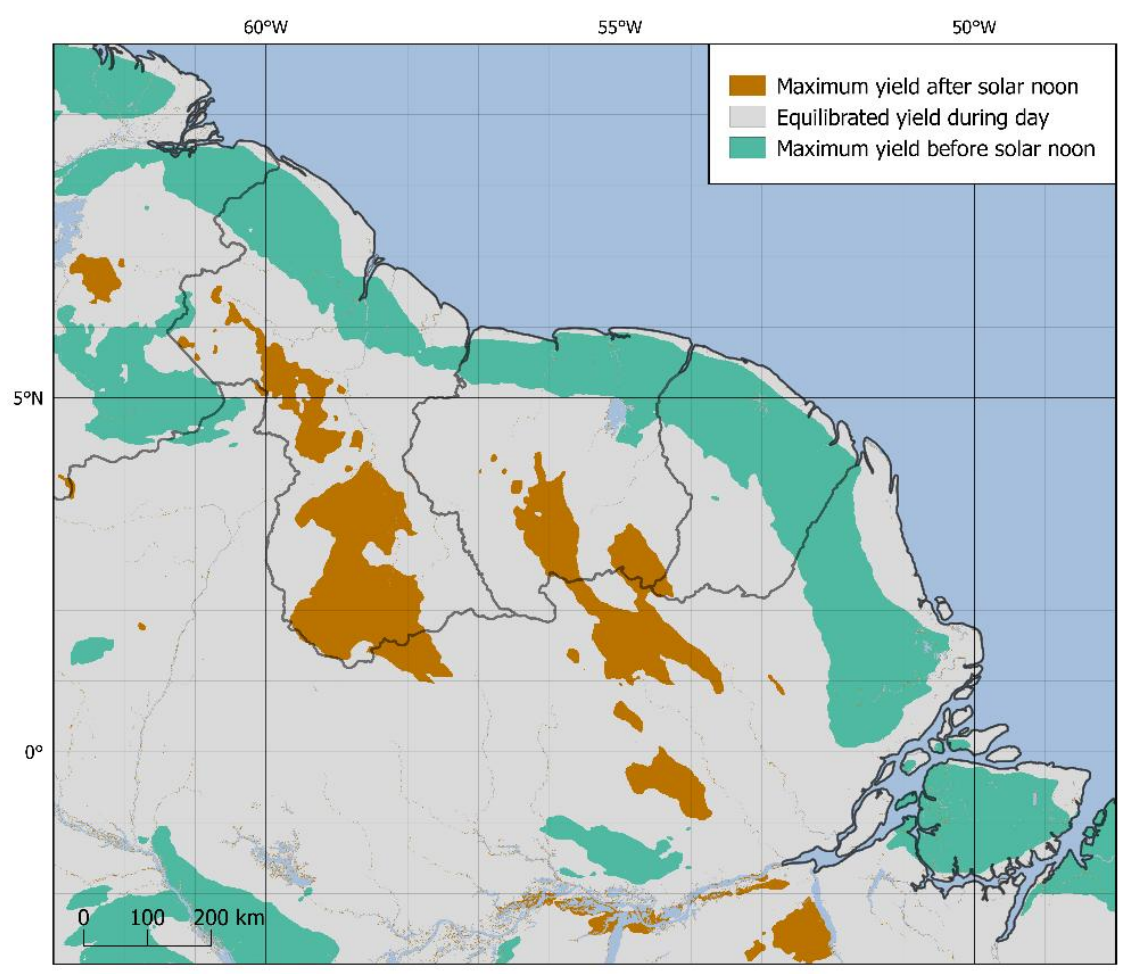

Figure 13. Map of orientation indicator

\section{Conclusions}

In this article, we have estimated the solar potential in the Guiana Shield and the operability of the solar resource. We used the Heliosat-2 method, optimized by Albarelo et al. [9], to exploit images of the geostationary meteorological satellite GOES. We estimated the global horizontal irradiation (GHI) and direct normal irradiation (DNI) for the entire area using the visible channel images from the GOES-13 satellite from April 2010 to July 2015, on an hourly basis and with a spatial resolution of $1 \mathrm{~km} \times 1 \mathrm{~km}$. The resulting time series allowed us to map the daily average global and direct solar radiation. In addition, we created indicator maps to identify:

- the annual average solar potential (GHI and DNI);

- operational areas that can be employed for solar systems, which correspond to areas with a slope less than $4 \%$. Consideration of the impacts of the land capability map decreased the suitable areas for solar power plants to $48.6 \%$;

- areas where exploitation of the solar resource is not viable due to insufficient energy potential, i.e. energy potential below a minimum threshold $\left(1600 \mathrm{kWh} \cdot \mathrm{m}^{-2} \cdot \mathrm{year}^{-1}\right.$ for GHI and $2000 \mathrm{kWh} \cdot \mathrm{m}^{-2}$.year ${ }^{-1}$ for DNI);

- inter-day variability of DNI and GHI over 5 years; 
- the optimum orientation of the solar panels in order to effectively exploit the solar resource.

This is the first study to produce spatiotemporal indicator maps on the exploitability of the solar resource. They bring new knowledge regarding the solar potential in the Guiana Shield and can help promote the exploitation of solar energy systems such as photovoltaic plants, solar water heaters (GHI), or solar concentrators (DNI). By making such knowledge available, the authors wish to contribute to the development of renewable energy and help mitigate climate change.

We aware that our research may have one limitation which lies in the limited number of ground stations used for the validation of the method. It would have been interesting to have better spatially distributed ground stations throughout the Guiana Shield to validate the radiation estimates.

Future work is planned in order to map the solar potential on the entire South American continent by validating radiation estimates from Baseline Surface Radiation Network (BSRN) stations present in the region.

\section{Acknowledgments}

The authors thank the FEDER European program in French Guiana, and Meteo France, who enabled the realization of this study within the SOLAREST research project. 
612 [1] International Energy Agency - Photovoltaic Power Systems Program. 2015. Trends 2015 in 613 Photovoltaic Applications.

614 [2] IRENA. 2015. Renewable Energy Policy Brief: Brazil. IRENA, Abu Dhabi.

615 [3] IRENA. 2015. Renewable Energy Policy Brief: Guyana. IRENA, Abu Dhabi.

616 [4] IRENA. 2015. Renewable Energy Policy Brief: Suriname. IRENA, Abu Dhabi.

617 [5] IRENA. 2015. Renewable Energy Policy Brief: Venezuela. IRENA, Abu Dhabi.

618 [6] Perez, R., Schlemmer, J., Renne, D., Cowlin, S., George, R. and Bandyopadhyay, B. 2009.

"Validation of the SUNY Model in a Meteosat Environment". Proceedings of ASES Annual Conference, Buffalo, New York.

[7] Pinker, R., and Laszlo, I. 1992. "Modeling Surface Solar Irradiance for satellite applications on a global scale." Journal of Applied Meteorology, Vol. 31, pp. 194-211.

[8] Janjai, S., Pankaew, P. and Laksanaboonsong, J. 2009. A model for calculating hourly global solar radiation from satellite data in the tropics. Applied Energy, Vol. 86, Issue 9, pp 1450-1457

[9] Cano, D., Monget, J.M., Albuisson, M., Guilllard, H., Regas, N. and Wald, L. 1986. "A method for the determination of the global solar radiation from meteorological satellite data". Solar Energy, Vol. 37, pp. 31-39.

[10] Rigollier, C., Lefèvre, M. and Wald, L. 2004. "The method Heliosat-2 for deriving shortwave solar radiation from satellite images”. Solar Energy, Vol. 77, No. 2, pp. 159-169.

[11] Perez R., P. Ineichen, K. Moore, M. Kmiecik, C. Chain, R. George and F. Vignola. 2002. A New Operational Satellite-to-Irradiance Model. Solar Energy, Vol. 73, 5, pp. 307-317.

[12] Martins, F., Pereira, E. and Abreu, S. 2007. "Satellite-derived solar resource maps for Brazil under SWERA project”. Solar Energy, Vol. 81, No. 4, pp. 517-528.

[13] Zhipeng Qu. La nouvelle méthode Heliosat-4 pour l'évaluation du rayonnement solaire au sol. PhD Thesis. Ecole Nationale Supérieure des Mines de Paris, 2013.

[14] Albarelo, T., Marie-Joseph, I., Primerose, A., Seyler, F., Wald, L. and Linguet, L. 2015. "Optimizing the Heliosat-II Method for Surface Solar Irradiation Estimation with GOES Images". Canadian Journal of Remote Sensing: Journal Canadien de télédétection, Vol. 41, No. 2, pp. 86-100.

[15] Janjai, S., Pankaew, P., Laksanaboonsong, J. and Kitichantaropas, P. 2011. "Estimation of solar radiation over Cambodia from long-term satellite data". Renewable Energy, Vol. 36, pp. 1214-1220.

641

642

643

644

645

646

647

648

649

650

651

652

653

[16] Janjai, S., Masiri, I. and Laksanaboonsong, J. 2013. "Satellite-derived solar resource maps for Myanmar". Renewable Energy, Vol. 53, pp. 132-140.

[17] Gastli, A. and Y. Charabi. 2010. « Solar electricity prospects in Oman using GIS-based solar radiation maps ». Renewable and Sustainable Energy Reviews, Vol. 14, pp. 790-797.

[18] Pillot, B., Muselli, M., Poggi, P. and Dias J. B. 2015. "Satellite-based assessment and in situ validation of solar irradiation maps in the Republic of Djibouti". Solar Energy, Vol. 120, pp. 603-619.

[19] Pereira, E.B., Martins, F.R., Abreu, S.L. and Rüther R. 2006. Atlas Brasileiro de Energia Solar. ISBN 978-85-17-00030-0. $60 \mathrm{p}$.

[20] Pereira, E., Martins, F., Abreu, S., Couto, P., Stuhlmann, R. and Colle, S. 2000. "Effects of burning of biomass on satellite estimations of solar irradiation in Brazil". Solar Energy, Vol. 68, No. 1, pp.91-107.

[21] Martins, F. and Pereira, E. 2006. "Parameterization of aerosols from burning biomass in the Brazil-SR radiative transfer model”. Solar energy, Vol. 80, pp. 231-239. 
[22] Martins, F., Pereira, E. and Abreu, S. 2007. "Satellite-derived solar resource maps for Brazil under SWERA project”. Solar Energy, Vol. 81, No. 4, pp. 517-528.

[23] Polo, J., Bernardos, A., Navarro, A.A., Fernandez-Peruchena, C.-M., Ramìrez, L., Guisado, M.V. and Martìnez, S. 2015. "Solar resources and power potential mapping in Vietnam using satellitederived and GIS-based information”. Energy Conversion and Management, Vol. 98, pp. 348-358.

[24] Mahtta, R., Joshi, P.K. and A.K. Jindal. 2014. "Solar power potential mapping in India using remote sensing inputs and environmental parameters". Renewable Energy, Vol. 71, pp. 255-262.

[25] Gherboudj, I. and Ghedira H. 2016. "Assessment of solar energy potential over the United Arab Emirates using remote sensing and weather forecast data". Renewable and Sustainable Energy Reviews, Vol. 55, pp. 1210-1224.

[26] Gond, V., Freycon, V., Molino, J.-F., Brunaux, O., Ingrassia, F. et al. 2011. "Broad-scale spatial pattern of forest landscape types in the Guiana Shield". International Journal of Applied Earth Observation and Geoinformation, pp. 357-367.

[27] Rigollier, C., Bauer, O. and Wald, L. 2000. "On the Clear Sky model of the ESRA - European Solar Radiation Atlas - with respect to the Heliosat method”. Solar Energy, Vol. 68, No. 1, pp. 33-48.

[28] Jarvis, A., H.I. Reuter, A. Nelson, E. Guevara, 2008. Hole-filled SRTM for the globe Version 4, available from the CGIAR-CSI SRTM 90m Database (http://srtm.csi.cgiar.org)

[29] Posselt, R., Mueller, R.W., Stöckli R., Trentmann, J. 2012. Remote sensing of solar surface radiation for climate monitoring - the CM-SAF retrieval in international comparison. Remote Sensing of Environment Vol. 118, pp. 186-198.

[30] Müller, Richard; Pfeifroth, Uwe; Träger-Chatterjee, Christine; Cremer, Roswitha; Trentmann, Jörg; Hollmann, Rainer. 2015. Surface Solar Radiation Data Set - Heliosat (SARAH) - Edition 1. Satellite Application Facility on Climate Monitoring. DOI:10.5676/EUM_SAF_CM/SARAH/V001.http://dx.doi.org/10.5676/EUM_SAF_CM/SARAH/V0 01

[31] Almorox, J., Benito, M. and Hontoria, C. 2008. "Estimation of Solar Radiation in Venezuela". Interciencia, Vol. 33, No. 4, pp. 280-283.

[32] WMO. 2008. Guide to Meteorological Instruments and Methods of Observation. WMO-No. 8. Geneva: World Meteorological Organization.

[33] Geiger M., Diabaté L., Ménard L., Wald L., 2002. A web service for controlling the quality of measurements of global solar irradiation. Solar Energy, Vol. 73, No 6, pp. 475-480

[34] SoDa - Solar radiation Data. http://www.soda-is.com/eng/index.html.

[35] Diabaté, L., Demarcq, H., Michaud-Regas, N. and Wald, L. 1988. “Estimating incident solar radiation at the surface from images of the Earth transmitted by geostationary satellites : the Heliosat Project “. International Journal of Solar energy, Vol. 5, pp. 261 -278.

[36] Nguyen, L., Doelling, D.R., Minnis, P. and Ayers, J.K. 2004. "Rapid technique to cross calibrate satellite imager visible channels". In Proceedings of SPIE 49Th Annual Meeting, Earth Observing Systems IX Conference, August 2-6, Denver, CO, United States. Vol. 5542, pp. 227-235.

[37] Rigollier, C. and Wald, L. 1998. "Using Meteosat images to map the solar radiation: improvements of the Heliosat method". In Proceedings of the 9th Conference on Satellite Meteorology and Oceanography.Published by Eumetsat, Darmstadt, Germany, EUMP22, pp.432-433.

[38] Hammer, A., Heinemann, D., Hoyer, C., Kuhlemann, R., Lorenz, E., Mueller, R. and Beyer, H.G. 2003. "Solar energy assessment using remote sensing technologies". Remote Sensing of Environment, Vol. 86, pp. 423-432.

[39] Beyer, H.G., Constanzo, C. and Heinemann, D. 1996. "Modifications of the Heliosat procedure for irradiance estimates from satellite images”. Solar Energy, Vol. 56, No. 3, pp.207-212. 
[40] Remund, J., Wald, L., Lefèvre, M., Ranchin, T. and Page, J. 2003. "Worldwide Linke turbidity information". In Proceedings of ISES Solar World Congress, 16-19 June 2003, Göteborg, Sweden.

[41] Lefèvre, M., Wald, L., and Diabaté, L. 2007. "Using reduced data sets ISCCP-B2 from the Meteosat satellites to assess surface solar irradiance." Solar Energy, Vol. 81: pp. 240-253.

[42] Aculinin, A. 2008. "Latitudinal variability of surface solar radiation in Moldova". Moldavian Journal of the Physical Sciences, Vol. 7, pp. 247-253.

[43] Abdel Wahab, M., El-Metwally, M., Hassan, R., Lefèvre, M., Oumbe, A. and Wald, L. 2010. "Assessing surface solar irradiance and its long-term variations in the northern Africa desert climate using Meteosat images". International Journal of Remote Sensing, Vol. 31, No. 1, pp. 261-280.

[44] Al-Jumaily, K.J, Al-Salihi, A.M. and Al-Tai, O.T. 2010. "Evaluation of Meteosat-8 measurements using daily global solar radiation for two stations in Iraq". International Journal of Energy and Environment, Vol. 1, pp. 635-642.

[45] Zhang, M., Liu, J., Li, G., Fan, J., Deng, H., Ren, J. and Chen, Z. 2011. “Solar Irradiance estimated from FY-2 data at some North China sites". In Proceedings of the Geoscience and Remote Sensing Symposium (IGARSS) 2011, July 24-29, Vancouver, BC, Canada, pp. 3284-3287.

[46] Météo-France. 2011. Le climat guyanais. ISBN 978-2-11-128228-5. 57p.

[47] Fontoynont, M., Dumortier, D., Heinemann, D., Hammer, A., Olseth, J.A., Skarveit, A., Ineichen, P., Reise, C., Page, J., Roche, L., Beyer, H.G. and Wald, L. 1997. "Satel-Light, Processing of Meteosat data for the production of high quality daylight and solar radiation data available on a World Wide Web Internet server. Mid-term progress report JOR3 - CT 95 - 0041". Project Satel-Light, for the Commission of the European Communities, Ecole Nationale des Travaux Publics de l'Etat, Vaulxen-Velin, France.

[48] Gschwind, B., Ménard, L., Albuisson, M. and Wald, L. 2006. "Converting a successful research project into a sustainable service: The case of the SoDa Web service". Environmental Modelling \& Software, Vol. 21, pp. 1555-1561.

[49] Blanc, P., Gschwind, B., Lefèvre, M. and Wald, L. 2011. "The HelioClim Project: Surface Solar Irradiance Data for Climate Applications". Remote Sensing, Vol. 3, pp.343-361.

[50] Pillot, B., Muselli, M., Poggi, P. and Dias J. B. 2015. "Satellite-based assessment and in situ validation of solar irradiation maps in the Republic of Djibouti". Solar Energy, Vol. 120, pp. 603-619

[51] Robbins N, Burger M. "Feasibility of Solar Power in South Africa and the existing barriers to its implementation". 4th Virtual International Conference on Advanced Research in Scientific Areas (ARSA-2015) Slovakia, November 9 - 13, 2015.

[52] International Energy Agency. 2010. World Energy Outlook 2010.

[53] Australian Renewable Energy Agency. 2015. Investigating the Impact of Solar Variability on Grid Stability. 